REVIEW

\title{
The links between axin and carcinogenesis
}

\author{
S Salahshor, J R Woodgett
}

J Clin Pathol 2005;58:225-236. doi: 10.1136/icp.2003.009506

The products of the two mammalian Axin genes (Axin) and its homologue Axin2) are essential for the degradation of $\beta$ catenin, a component of Wnt signalling that is frequently dysregulated in cancer cells. Axin is a multidomain scaffold protein that has many functions in biological signalling pathways. Overexpression of axin results in axis duplication in mouse embryos. Wnt signalling activity determines dorsal-ventral axis formation in vertebrates, implicating axin as a negative regulator of this signalling pathway. In addition, Wnts modulate pattern formation and the morphogenesis of most organs by influencing and controlling cell proliferation, motility, and fate. Defects in different components of the Wnt signalling pathway promote tumorigenesis and tumour progression. Recent biochemical studies of axins indicate that these molecules are the primary limiting components of this pathway. This review explores the intriguing connections between defects in axin function and human diseases.

See end of article for authors' affiliations

Correspondence to: Correspondence to:
Dr S Salahshor, Ontario Cancer Institute, Division of Experimental Therapeutics, 610 University Ave, M5G 2M9, Toronto, ON, Canada; Salahsho@ Uhnres.Utoronto.Ca

Accepted for publication 26 October 2004
A xin was originally identified as the product of the mouse gene called "fused" or fu (renamed Axin), and has since been shown to play a crucial role in controlling axis formation during embryonic development. Axin overexpression in frog embryos inhibits dorsal axis formation. Furthermore, mutation of the mouse gene "fused" was found to cause axis duplication in homozygous mouse embryos. ${ }^{1}$ Wnt signalling activity determines dorsal-ventral duplication in vertebrates and these results suggested that Axin somehow negatively regulates this signalling pathway. The subsequent demonstration of the effect of Axin on $\beta$ catenin concentrations, together with its biallelic inactivation in some human hepatocellular carcinomas (HCCs), indicated that Axin is a tumour suppressor gene. ${ }^{2}$ To date, axin has been implicated in at least three different signalling pathways: the stress activated protein kinase (SAPK), transforming growth factor $\beta$ (TGF $\beta$ ), and Wnt signalling pathways (fig 1). The multimeric nature of axin complexes suggests that axin might play an important role in other cell signalling systems, in addition to the coordination of these signals.

"The effect of Axin on $\beta$ catenin concentrations, together with its biallelic inactivation in some human hepatocellular carcinomas, indicated that Axin is a tumour suppressor gene"

\section{WNT SIGNALLING}

The Wnt signalling pathway regulates cellular proliferation, differentiation, and motility and is essential for development and morphogenesis..$^{3-5}$ Alterations in protein phosphorylation status are central to the regulation of Wnt signalling. Several components of the Wnt signalling pathway-including axin, adenomatous polyposis coli (APC), glycogen synthase kinase 3 (GSK3; both GSK $\beta$ and GSK $\alpha$ ), and $\beta$ cateninare phosphoproteins that are regulated through phosphorylation. In unstimulated cells, GSK $3 \alpha$ and GSK3 $\beta$ phosphorylate cytoplasmic $\beta$ catenin, which creates a recognition motif for $\beta$ transducin repeat containing protein, an E3 ubiquitin ligase. ${ }^{6}$ The ubiquitinylated $\beta$ catenin is rapidly degraded by the $26 \mathrm{~S}$ proteasome, ensuring that cytoplasmic concentrations of $\beta$ catenin are very low. Secreted Wnt ligands act on the cell surface receptor Frizzled and activate Dishevelled (DVL) through a poorly understood mechanism. Activated DVL binds and inhibits the phosphorylation of $\beta$ catenin by GSK3 $\beta / \alpha$, blocking $\beta$ catenin degradation (fig 2 ), so that $\beta$ catenin accumulates and translocates to the nucleus, where it interacts with the $\mathrm{T}$ cell specific factor (TCF)/lymphoid enhancer binding factor 1 (LEF1) transcription factor and induces the transcription of target genes such as c-jun, c-myc, and cyclin D $1^{7-11}$ Several in vitro and in vivo studies suggest that axins serve as scaffold proteins that bind directly to many proteins involved in the Wnt signalling pathway, and promote the phosphorylation of $\beta$ catenin by driving the formation of a complex with APC and GSK3. ${ }^{12-14}$

The $\beta$ catenin molecule is crucial in this pathway and shows abnormal expression and localisation in a wide variety of human cancers. ${ }^{15}$ In recent years, so called "canonical" Wnt signalling has received considerable attention because many components of this signalling cascade have been shown to play a role in tumorigenesis. ${ }^{1}$ The concentration of $\beta$ catenin in cells is tightly regulated by the APC-axin-GSK3 destruction complex. ${ }^{16}$ APC, another component

Abbreviations: aa, amino acids; $A D$, Alzheimer's disease; APC, adenomatous polyposis coli; CKI/II, casein kinase I/II; DIX, Dishevelled and axin binding domain;

DVL, Dishevelled; Frat, frequently rearranged in activated $T$ cells; GSK3, glycogen synthase kinase 3; HB, hepatoblastoma; HCC, hepatocellular cancer; JNK, Jun $\mathrm{N}$-terminal kinase; LEF-1, lymphoid enhancer binding factor 1; MB, medulloblastoma; MEKK1, mitogen activated protein/extracellular regulated kinase kinase kinase 1; MID, MEKK binding domain; PP2A, protein phosphatase 2A; RGS, regulator of $G$ protein signalling; SAPK, stress activated protein kinase; SCC, oesophageal squamous cell carcinoma; TCF, T cell specific factor; TGF $\beta R$, transforming growth factor $\beta$ receptor 
A

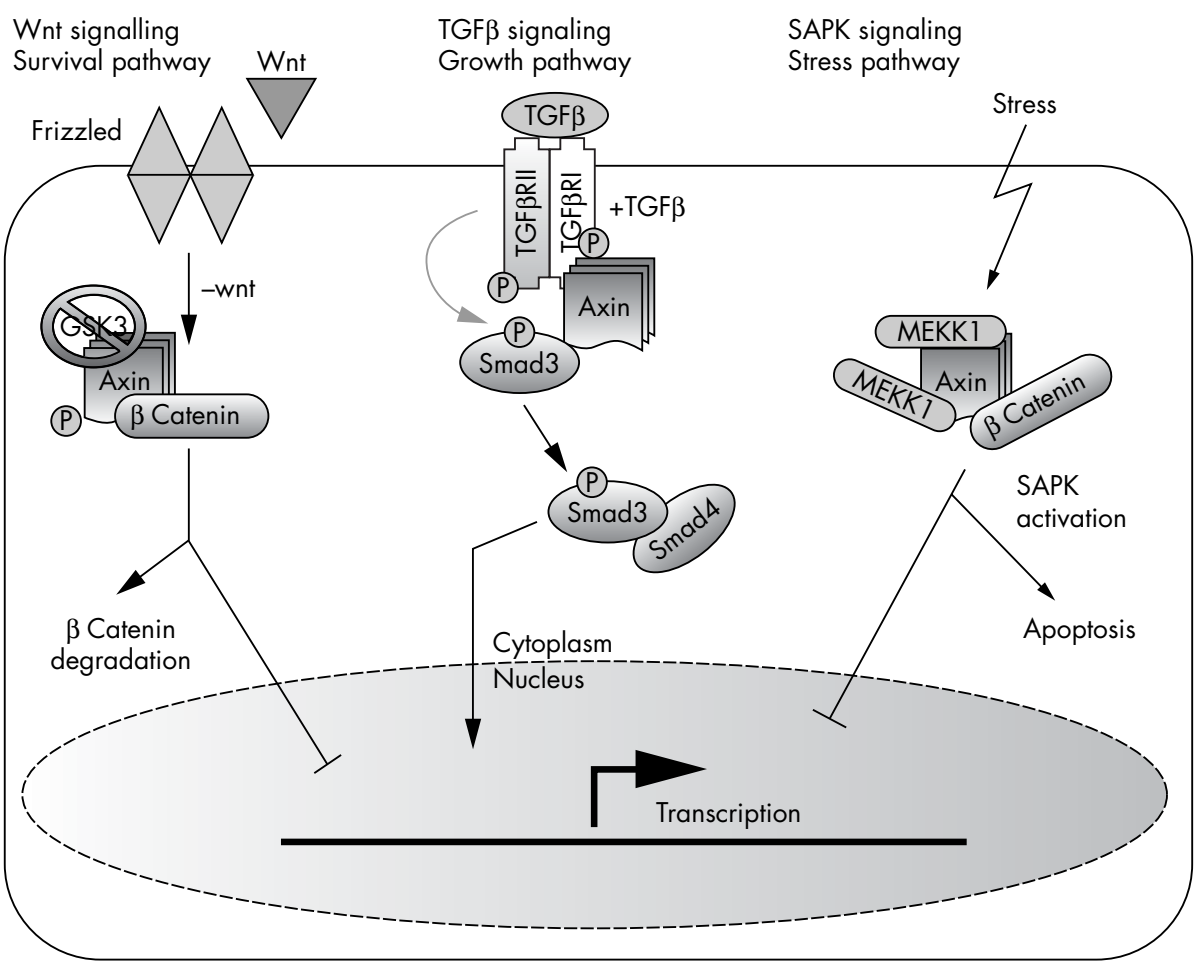

Figure 1 At least three different signalling pathways are regulated by axin. (A) In the absence of Wnt ligands, axin stimulates $\beta$ catenin

phosphorylation and subsequent protease mediated degradation limits its transcriptional activity. (B) In the presence of transforming growth

factor $\beta$ (TGF $\beta$ ) signals, axin stimulates Smad phosphorylation by TGF $\beta$ receptors (TGF $\beta$ receptors I and II). The activated Smads then translocate to the nucleus and activate transcription of downstream target genes. (C) In cells subjected to stress, axin binds to mitogen activated protein/extracellular regulated kinase kinase kinase 1 (MEKK1) and stimulates stress activated protein kinase (SAPK)/JNK (Jun Nterminal kinase) mediated apoptosis. GSK3, glycogen synthase kinase 3 . of Wht signalling, is mutated in most $(\sim 70 \%)$ human colorectal cancers and is also linked to familial adenomatous polyposis. ${ }^{17}$ Inappropriate activation of Wnt signalling by mutation of different components of this pathway has been seen in a large number of other human cancers including colon carcinoma, ${ }^{18}{ }^{19}$ medulloblastoma, ${ }^{20}{ }^{21}$ melanoma, ${ }^{22}$ hepatocellular carcinoma, ${ }^{23}$ and ovarian and uterine cancer. ${ }^{24-26}$ Although both $\beta$ catenin and Wnt are positive regulators of the pathway and have been identified as protooncogenes, APC and axin are considered as negative effectors of the pathway and function as tumour suppressors. ${ }^{27}$ This model asserts that because axin-APC-GSK3 mediated degradation of $\beta$ catenin is inhibited by either Wnt signals or mutation of components of the Wnt signalling pathway, the concentration of $\beta$ catenin in cells is raised, leading to increased cell proliferation and cancer.

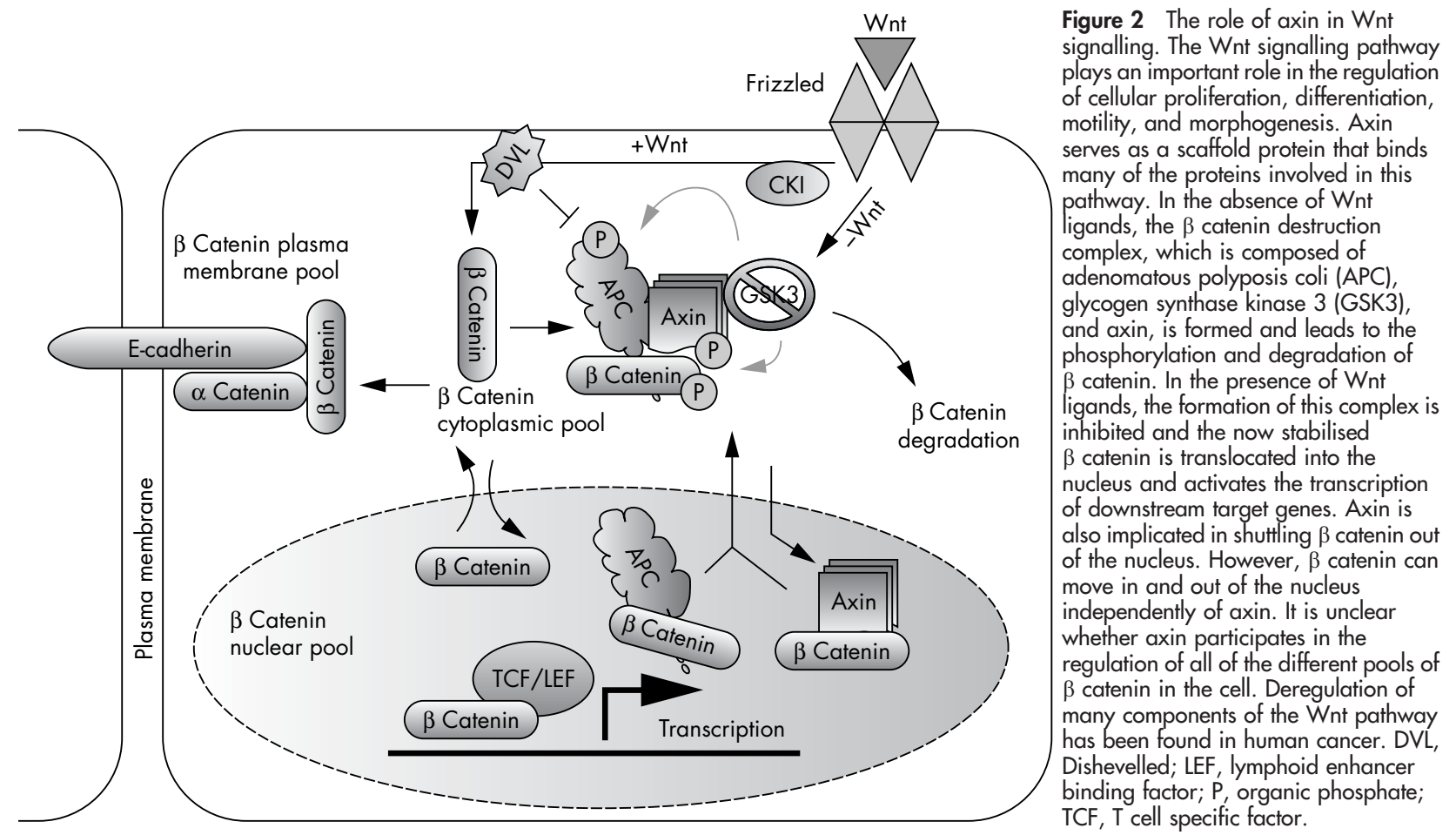




\section{TGF $\beta$ SIGNALLING}

Similar to the Wnt signalling pathway, TGF $\beta$ signalling regulates several cellular functions, often in concert with Wnt signalling, including proliferation, differentiation, migration, and apoptosis. ${ }^{28}$ TGF $\beta$ also plays an important role in carcinogenesis. Upon stimulation, TGF $\beta$ receptors phosphorylate Smads-the TGF $\beta$ effector proteins (fig 1B). ${ }^{29}$ The phosphorylated Smads then translocate into the nucleus, where they regulate the transcription of target genes. Although TGF $\beta$ can often appear to have different effects in different cell types, its primary effect on colonic epithelial cells is to reduce proliferation and induce differentiation. ${ }^{30}$ Mutations of the TGF $\beta$ receptors are often found in cancer cells with defects in mismatch repair systems. ${ }^{31}$ Axin has been shown to regulate the TGF $\beta$ signalling pathway by acting as an adaptor for Smad3, one of the TGF $\beta$ effectors (fig 1B). ${ }^{32}$ Both axinl and axin2 physically interact with Smad3 through interaction with a domain that is located between the $\beta$ catenin and DVL binding domains within the C-terminal region. The binding of DVL to axin has been shown to inhibit axin mediated downregulation of $\beta$ catenin. Although both Smad3 and DVL interact with the same region of axin, biochemical studies have shown that the interaction of DVL with axin does not compete with Smad3 binding to axin. Colocalisation of axin with Smad2 and Smad3 in the cytoplasm has been observed. Upon receptor activation, Smad3 bound to axin is efficiently phosphorylated by TGF $\beta$ receptor 1 and dissociates from the axin complex. Thus, axin may facilitate the phosphorylation and transcriptional activity of Smad3. ${ }^{32}$ TGF $\beta$ is one of the anti-oncogenic factors that inhibit nuclear $\beta$ catenin signalling in the Wnt pathway. Smad4, another effector of TGF $\beta$, has been shown to facilitate Wnt signalling through interaction with $\beta$ catenin and TCF/LEF. ${ }^{33}$ Although axin is a negative regulator of the Wnt signalling pathway, it facilitates TGF $\beta$ signalling. These results indicate that axin has a dual function in signal transduction-acting as a negative regulator of the Wnt signalling pathway and as a positive regulator of the TGF $\beta$ signalling pathway. Deregulation of both pathways is frequently detected in human cancer cells.

\section{SAPK/JNK SIGNALLING}

The SAPK/JNK (stress activated protein kinase/Jun Nterminal kinase) signal transduction pathway is activated in cells in response to stress. It is also involved in many normal physiological processes including tissue morphogenesis, cell proliferation, cell survival, and cell death. ${ }^{34}$ Depending on the cell type or the context of activation of other signalling pathways, SAPK/JNK can help mediate cell survival or apoptosis. $^{35}{ }^{36}$ Overexpression of axinl in cells stimulates SAPK/JNK and can induce apoptosis through the activation of MEKK (mitogen activated protein/extracellular regulated kinas kinase kinase). ${ }^{37}$ A MEKKl interacting domain (MID) on axin is flanked by the APC and GSK3 binding sites (fig 3A), and the C-terminal region of axin, which contains an oligomerisation domain, is necessary for SAPK activation (fig 3A). The effect of axin on the induction of apoptosis is mediated by SAPK/JNK activation and the destabilisation of $\beta$ catenin. ${ }^{39}$ The importance of the axinMEKK interaction and subsequent SAPK/JNK activation has been shown by the Axinl mutations found in cancer cells that are resistant to apoptosis. ${ }^{29-41}$ Induced expression of Axin in transgenic mice leads to massive cell death in different organs as a consequence of the increased capacity to degrade $\beta$ catenin. ${ }^{42}$ The introduction of wild-type Axin 1 into heptocellular and colorectal cancer cells induces apoptosis in a SAPK/JNK dependent manner. GSK3 competes with a MEKK binding site on axinl and thereby inhibits SAPK/JNK induced apoptosis. This is consistent with observations that
GSK3 can prevent cell death under certain circumstances. ${ }^{43}$ Thus, axin can bind to either GSK3 or MEKKl and form distinct complexes with opposing effects on apoptosis. Although axin can be "switched" to activate the SAPK/JNK pathway instead of Wnt signalling, it is still capable of downregulating $\beta$ catenin. ${ }^{44}$ Axin domains essential for Wnt signalling activation are distinct from those domains required for SAPK/JNK activation.

\section{"Depending on the cell type or the context of activation of other signalling pathways, SAPK/JNK can help mediate cell survival or apoptosis"}

MEKK4, which is related to MEKKl, was recently identified as another axin binding protein that mediates SAPK/JNK activation. ${ }^{45}$ Interestingly, MEKKl and MEKK4 compete for axin binding, even though the binding domain for MEKK4 is separate from the MEKKl binding domain. ${ }^{46}$ Axin dimerisation and oligomerisation appear to be necessary for the activation of the SAPK/JNK pathway. ${ }^{37}$ Other components of Wnt signalling such as GSK3 and CKI€ (casein kinase $\mathrm{I} \epsilon$ ) also compete for binding to axin, and thereby inhibit SAPK/JNK signalling, whereas the binding of APC and $\beta$ catenin to axin does not interfere with axin mediated SAPK/JNK activation. ${ }^{44}$

\section{AXIN GENE STRUCTURE, EXPRESSION, AND SUBCELLULAR LOCALISATION}

Axinl (also simply called Axin), which encodes isoforms a and b, and Axin2 (also called Axil or Conductin) have 45\% identity at the nucleotide level and the proteins they encode appear to be functionally similar. However, whereas Axinl is expressed ubiquitously during mouse embryogenesis, Axin2 is expressed in a restricted pattern. ${ }^{1}$ Axinl is the constitutively expressed component of the $\beta$ catenin degradation complex and is essential for the maintenance of low Wnt signalling activity in the basal state. In contrast, axin2 is upregulated in response to increased $\beta$ catenin concentrations and thus serves to limit the duration and intensity of the Wnt signal. ${ }^{47}{ }^{48}$ Axin is downregulated in a Wnt dependent manner and is dephosphorylated after Wnt stimulation, which leads to axinl destabilisation over time. Cells that receive Wnt ligand signals have low concentrations of axin. Biochemical studies show that the intracellular concentrations of axin are approximately 1000 times lower than those of other destruction complex components, suggesting that axin is the limiting factor in this pathway. ${ }^{49}$

\section{Axin 1}

Axinl was first identified as the product of the mouse fused locus. Its human homologue was mapped to chromosome 16 p13.3 and shows $87 \%$ similarity to the mouse protein. ${ }^{1}$ Axinl "isoform a" encodes a 862 amino acid (aa) polypeptide (GenBank NP_003493), whereas "isoform b" is a shorter form of axin lacking 36 aa within the N-terminal domain encoded by exon 8 (GenBank NP_851393) (fig 3A). The function of the polypeptide region encoded by exon 8 is as yet unknown (fig 4A). This splice form is conserved between different species, suggesting a conserved role. The polypeptide encoded by exon 8 is located between the $\beta$ catenin binding and Dishevelled and axin binding domain (DIX) domains (fig 3A). The region contains a predicted CKI phosphorylation site and is also close to the axin oligomerisation site, where axin binds to itself. It has been suggested that axin dimerisation is necessary for its stability and function in cells. The spliced exon is also located between two potential axin nuclear export signals. ${ }^{50}$ 

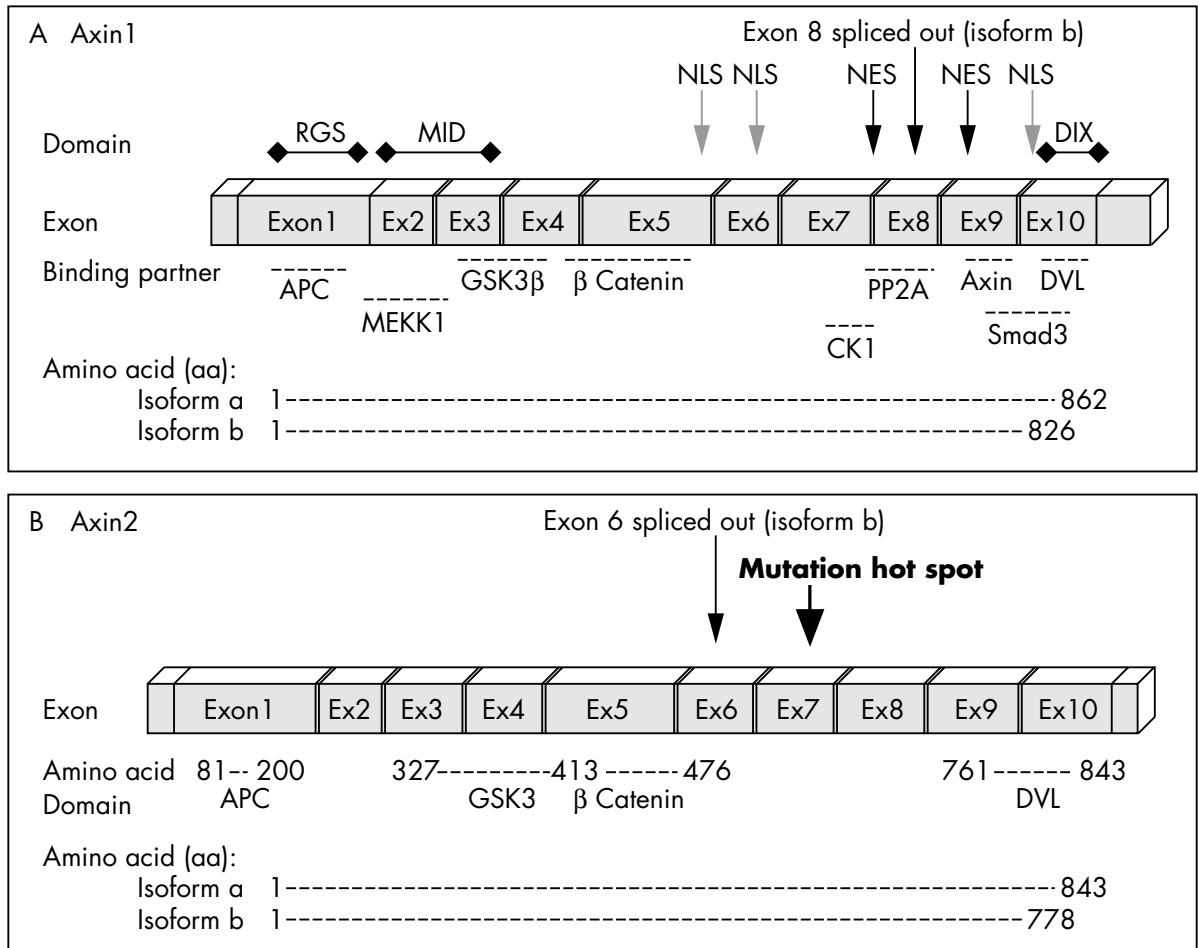

Figure 3 Genomic structure of Axin. (A) Axin 1 is composed of 10 exons (encoding isoform a). Exon 8 is spliced out in isoform b. (B) Axin2 also consists of 10 exons that encode 843 amino acids (aa) (isoform a) or a 778 aa polypeptide (isoform b). Similar to Axin 1, the binding partners of Axin2 are APC (aa 81-200), GSK3 (aa 372413 ), $\beta$ catenin (aa 414-476), and DVL (aa 761-843). So far, all mutations found in Axin2 are located in exon 7. APC, adenomatous polyposis coli; CKI, casein kinase I; DIX, Dishevelled and axin binding domain; DVL, Dishevelled; GSK3, glycogen synthase kinase 3; MEKK 1 mitogen activated protein/ extracellular regulated kinase kinase kinase 1; NES, nuclear export signal; NLS, nuclear localisation signal; PP2A, protein phosphatase.

\section{Axin 2}

A homologue of axin, axin2 was identified by virtue of its interaction with $\beta$ catenin. ${ }^{16} 5152$ Mutation of the Axin2 gene leads to an increase in $\beta$ catenin concentrations in colorectal cancers with defective mismatch repair systems. ${ }^{53}$ Molecular studies revealed that Axin2 contains 10 exons spanning more than $2.5 \mathrm{~kb} .{ }^{54}$ Similar to Axin 1, Axin2 encodes two isoforms ( $a$ and $b$ ). In isoform $b$, exon 6 is spliced out, leading to a transcript with 65 fewer aa (S Salahshor, unpublished data, 2004). Fluorescence in situ hybridisation analysis assigned it to human chromosome $17 \mathrm{q} 24$, a region that shows frequent loss of heterozygosity in breast cancer, neuroblastoma, and other tumours. ${ }^{54}$ Similar to Axinl, Axin2 has binding domains for APC, GSK3, and $\beta$ catenin (fig 3B). ${ }^{16}$

\section{Subcellular localisation}

Based on the known function and proposed activities of axin, both axins are expected to be located in the cytoplasm of cells where they promote $\beta$ catenin phosphorylation and degradation. Confocal microscopy of whole mount crypts from patients with colorectal cancer shows that staining for axin l is diffuse within the nucleus and along lateral cell membranes where $\beta$ catenin is located, and also in the cytoplasm where both GSK3 and the cytoplasmic pool of $\beta$ catenin are found. Cell lysate fractionation of two human epithelial cell lines-HCT116 (colorectal cancer cells with $\beta$ catenin mutation) and HEK293 (embryonic kidney cells)—reflects the axin localisation pattern seen in tissue. Although axinl was found mainly in the nucleus of HCT116 cells, in HEK293 cells it was localised in both the nuclear and cytoplasmic compartments. ${ }^{55}$ Staining for axinl is seen in the cytoplasm of normal epithelial cells, whereas it is located in the nucleus in adenocarcinomas and tumours (fig 4B). The subcellular localisation of axinl appears to be cell type dependent (fig 5). In contrast, axin2 shows strong nuclear staining in normal tissue. Nuclear localisation of axin2 could also be detected in polyps and carcinomas with some cytoplasmic translocation. ${ }^{55}$ Despite the similarity between these two molecules, it appears that they are not found within the same compartment of the cell, and thus may have distinct functions. Axinl can shuttle between the cytoplasm and the nucleus and act as a $\beta$ catenin chaperone. Two nuclear export (between aa 532 and 667) and three nuclear import signals have been identified on axinl (fig 3A). Axinl translocation to the nucleus and its interaction with $\beta$ catenin is required for axin induced cytoplasmic shifting of $\beta$ catenin. ${ }^{50} 56$
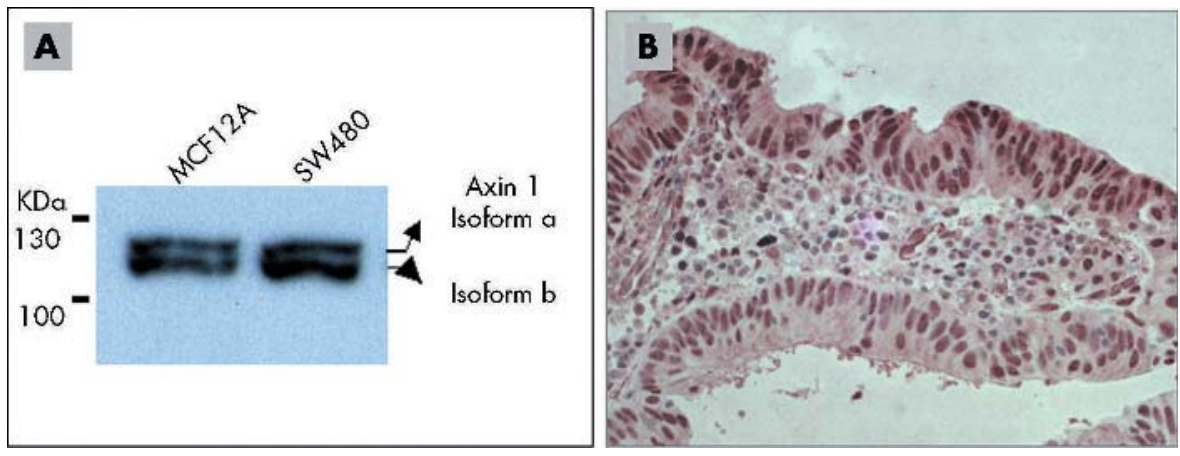

Figure 4 Axin expression pattern and subcellular localisation in tumour cell lines and tumour tissue. (A) Western blot analysis of protein extracted from MCF12A and SW480 cells confirmed the existence of two axinl isoforms la and b). (B) The subcellular localisation of axinl was examined in a sporadic colorectal cancer case and axinl was found to have a predominantly nuclear localisation. 

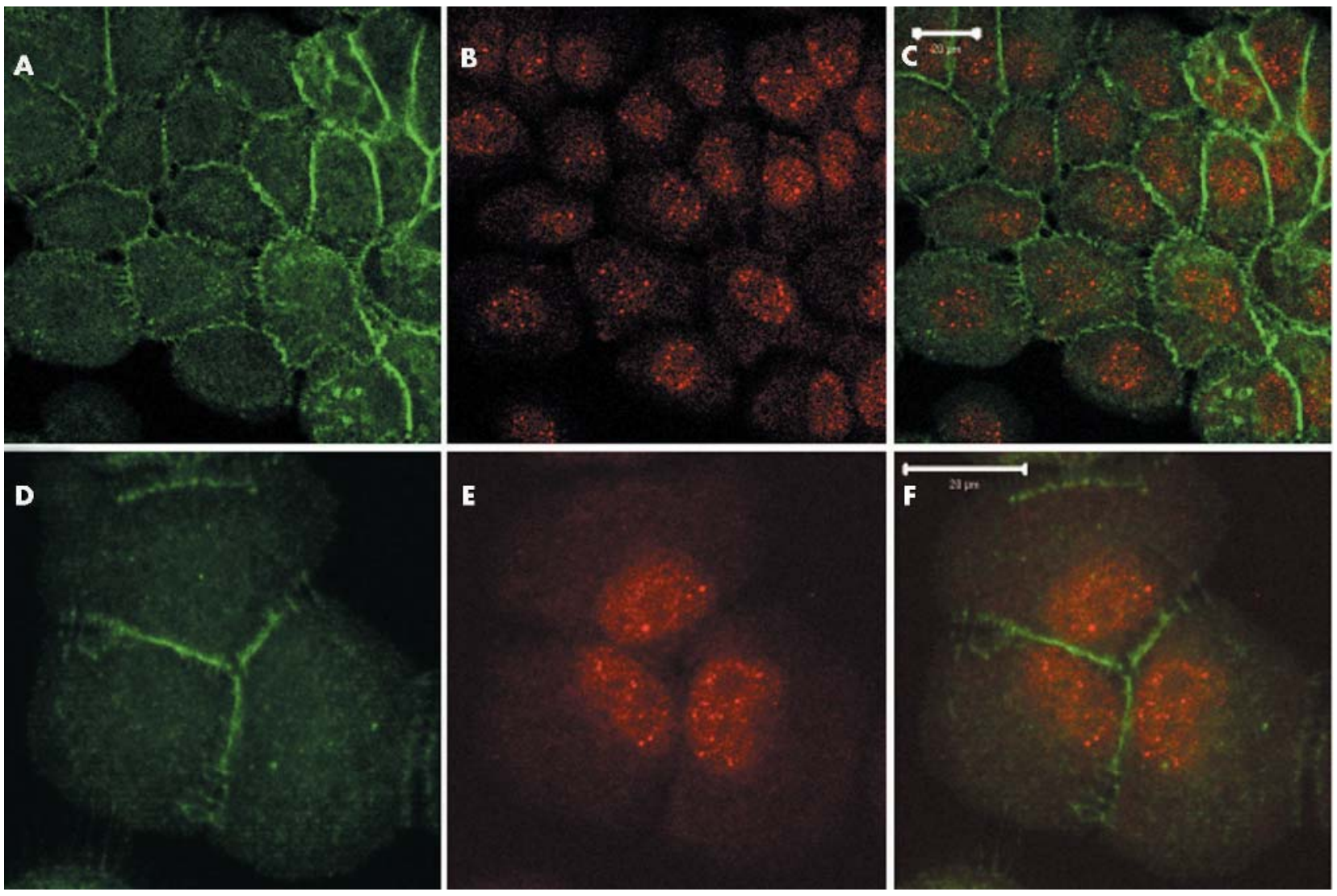

Figure 5 Subcellular localisation of axin 1 in MCF12A cells. Based on the known function of axin 1, it is expected to be mainly localised in the cytoplasm. Confocal sections of MCF12A cells stained with (A and D) anti-axin 1 and ( $B$ and $E$ ) anti- $\beta$ catenin antibodies ( $C$ and $F$ merged) show both nuclear and cyłoplasmic axin 1 staining, with a pronounced nuclear localisation, whereas $\beta$ catenin is located mainly at the cell membrane (scale bars, $20 \mu \mathrm{m})$. The following antibodies were used: polyclonal anti-axin 1 (1/500 dilution; Zymed, South San Francisco, California, USA), monoclonal anti$\beta$ catenin antibody (1/500 dilution; Signal Transduction Laboratories; Lexington, Kentucky, USA), secondary monoclonal and polyclonal antibodies (1/1000 dilution; Molecular Probes, Eugene, Oregon, USA). Other studies show a more cytoplasmic localisation for axin 1. However, the subcellular localisation of axin 1 appears to be cell type dependent.

\section{AXIN BINDING PARTNERS}

Both axins contain several domains that mediate direct binding to low density lipoprotein related protein receptor, the Frizzled coreceptor, ${ }^{57-59}$ APC (which appears to assist axin in recruiting $\beta$ catenin to the axin complex), ${ }^{13} \mathrm{GSK} 3 \beta / \alpha,{ }^{60}$ $\beta$ catenin. ${ }^{61}{ }^{62}$ DVL (DVL-1, DVL-2, and DVL-3), ${ }^{63}$ MEKK1, $\mathrm{CKI},{ }^{64}$ protein phosphatase $2 \mathrm{~A}(\mathrm{PP} 2 \mathrm{~A}),{ }^{65}$ frequently rearranged in advanced $\mathrm{T}$ cell lymphomas (Fratl), ${ }^{66}$ and $\mathrm{a}$ homodimerisation domain (figs 3 and 6). ${ }^{67}$

\section{APC}

The region of axin involved in APC binding shows significant homology to members of the regulators of $G$ protein signalling (RGS) family. ${ }^{12}$ The region of APC that interacts with axin consists of a conserved sequence of approximately 20 aa containing a Ser-Ala-Met-Pro (SAMP) motif. ${ }^{16}$ The APC gene contains three SAMP repeat sequences, all of which are located after its mutation cluster region, where most truncating mutations in cancer are found. These mutations eliminate all axin binding sites on APC, but preserve some of the $\beta$ catenin binding domains, indicating the important role that the interaction between axin and APC plays in APC tumour suppressor activity. ${ }^{22}$ Thus, the tumorigenic potential of mutated APC correlates with loss of binding to axinl/ axin2, rather than loss of $\beta$ catenin binding. APC binding to axin via its RGS domain is required for the efficient downregulation of $\beta$ catenin by APC. ${ }^{22}{ }^{51}$ However, overexpression of axin in colorectal cancer cell lines bearing a mutated form of APC that lacks an axin binding domain can still promote $\beta$ catenin downregulation. ${ }^{16}{ }^{6169}$ Similarly, axin mutants lacking the APC binding domain are still capable of $\beta$ catenin downregulation when overexpressed. ${ }^{51}{ }^{62}$ These results suggest that APC might be only a cofactor for axin l/ axin2. However, multiple binding sites on APC for $\beta$ catenin ( 10 binding sites) and axinl/axin2 (three binding sites) may be important for the efficient assembly of the $\beta$ catenin degradation machinery in different cell types or various in vivo conditions. These results further indicate that the concentration of axin rather than its interaction with other components of Wnt signalling might control its activity in cells, and that axin is the rate limiting factor in these reactions. In contrast, in SW480 colorectal cancer cell lines, which carry a truncated form of APC, $\beta$ catenin is stabilised. Expression of ectopic APC leads to $\beta$ catenin degradation..$^{22} 70$ Endogenous axinl and axin 2 are present in this cell line, but appear not be capable of downregulating $\beta$ catenin in the absence of wild-type APC.

"Direct binding of APC to $\beta$ catenin is not essential for APC to degrade $\beta$ catenin, whereas the binding of axin to $\beta$ catenin is necessary for it to degrade $\beta$ catenin"

However, overexpression of exogenous axin2 can induce $\beta$ catenin degradation in SW480 colon carcinoma cells. Overexpression of an axin 2 mutant that lacks the $\beta$ catenin binding domain does not induce $\beta$ catenin degradation, whereas an axin2 mutant lacking the RGS domain (APC 


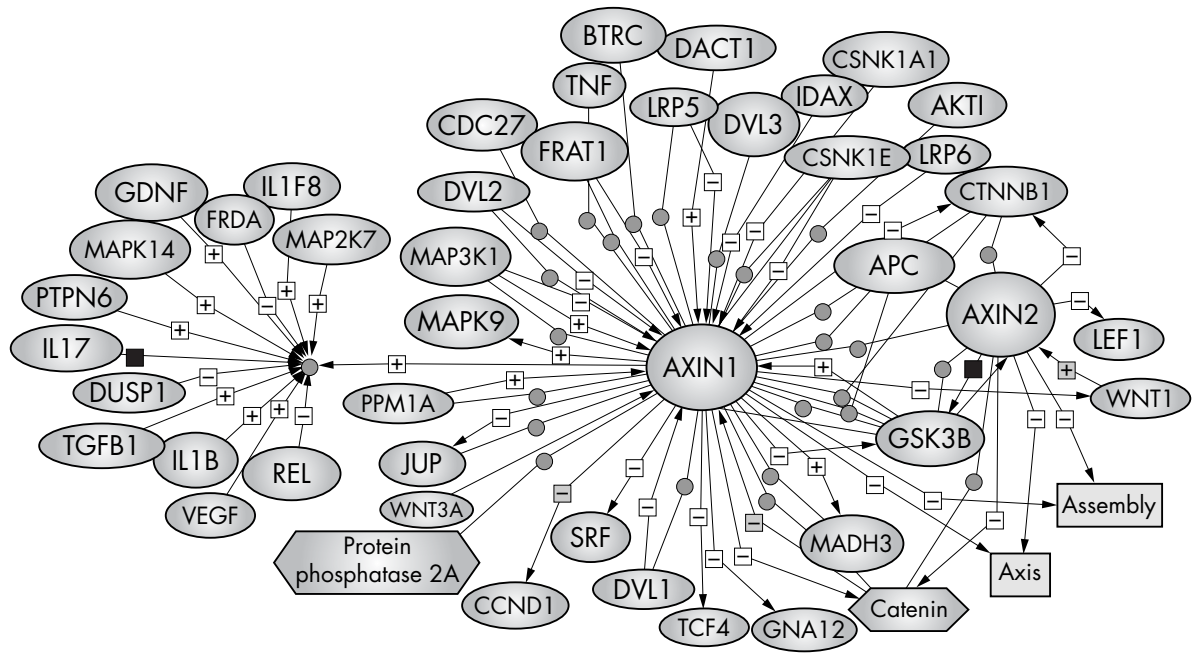

Figure 6 Axin regulators and binding partners. To bring all the relevant information about axin together, we have used PathwayAssist soffware (Stratagene) to generate a network of molecules that are either positively $(+)$ or negatively $(-)$ regulated by axin. Each interaction is annotated with the source references and contains hyperlinks to the source literature on PubMed. The biological data have been extracted from PubMed. The references that support the interaction or regulation for each molecule can be viewed by holding the mouse on the plus or minus sign. This pathway is an online navigation tool (http:// kinase.uhnres.utoronto.ca/Sima/ axins_pathway/). binding domain) can induce degradation. ${ }^{16} \mathrm{~A} \quad \beta$ catenin mutant that does not interact with axin2 is resistant to degradation induced by the ectopic expression of axin 2 in SW480 cells. However, these $\beta$ catenin mutants were efficiently degraded when wild-type APC was introduced. ${ }^{71}$ These observations indicate that direct binding of APC to $\beta$ catenin is not essential for APC to degrade $\beta$ catenin, whereas the binding of axin2 to $\beta$ catenin is necessary for it to degrade $\beta$ catenin.

\section{$\beta$ Catenin}

Axinl has been shown to interact directly with $\beta$ catenin at residues adjacent to the GSK3 $\alpha / \beta$ binding domain, ${ }^{12}$ and $\beta$ catenin binding to axin 2 is abolished or strongly reduced by mutations in $\beta$ catenin ARM (armadillo repeat) 3 and $4 .{ }^{71} \mathrm{~A}$ direct interaction between axin 2 and $\beta$ catenin in the same region as axinl has been shown. This interaction promotes the phosphorylation of $\beta$ catenin by CKI $\alpha$ and GSK3, which is required for the ubiquitination and subsequent degradation of $\beta$ catenin. The degradation of $\beta$ catenin can also occur in a GSK3/CKI $\alpha$ phosphorylation independent manner. Siab (mammalian homologue of drosophila gene sina) binds to the ubiquitin conjugating enzyme through its $\mathrm{N}$-terminal region and forms a complex with Ebi. Ebi is an F-box protein that binds to $\beta$ catenin and forms a complex that functions as a ubiquitin ligase and is able to downregulate $\beta$ catenin in a p53 inducible manner. ${ }^{72}{ }^{73}$ Recently, it was shown that activated p53 can downregulate $\beta$ catenin. It was suggested that p53 induces the faster mobilisation of axin into the $\beta$ catenin degradation complex, and thereby stimulates $\beta$ catenin degradation. ${ }^{74}$ These observations imply that axin might be able to promote the degradation of $\beta$ catenin, through both phosphorylation dependent and independent pathways.

\section{GSK3}

GSK $3 \alpha$ and GSK3 $\beta$ are essential players in the $\beta$ catenin destruction complex. GSK $3 \alpha / \beta$ are serine/threonine kinases that phosphorylate three conserved serine and threonine residues in the $\mathrm{N}$-terminal domain of $\beta$ catenin. ${ }^{75}{ }^{76} \beta$ Catenin is a poor substrate of GSK3 in vitro, and GSK3 does not bind $\beta$ catenin directly, requiring axin and APC to facilitate its interaction with the $\beta$ catenin target. ${ }^{177}{ }^{78}$ Axin l dramatically (> 20000 times) facilitates the phosphorylation of APC and $\beta$ catenin by GSK3 in vitro. ${ }^{61}$ Phosphorylation by GSK3 $\alpha / \beta$ requires a priming phosphorylation by a third party kinase. In the case of $\beta$ catenin, this priming enzyme is CKI $\alpha .{ }^{79}$ Axin itself is phosphorylated by GSK $3 \alpha / \beta$ and this modification increases its stability. ${ }^{80}$ Unphosphorylated axin has a lower affinity for $\beta$ catenin, reducing its ability to promote the formation of the $\beta$ catenin destruction complex. ${ }^{27}{ }^{80} 81$ Axin 1 contains several possible GSK3 $\alpha / \beta$ phosphorylation sites, and mutation of these leads to reduced axin phosphorylation by GSK3.

\section{"Axin 1 dramatically facilitates the phosphorylation of APC and $\beta$ catenin by glycogen synthase kinase 3 in vitro"}

In drosophila, expression of a hypomorphic allele of Armadillo (the fly homologue of $\beta$ catenin) on a background lacking Zeste-White3/Shaggy (the fly homologue of GSK3), revealed that the concentration of $\beta$ catenin/Armadillo was still sensitive to expression of Wingless, the fly homologue of Wnts. This effect was mediated by changes in the concentration of axin. ${ }^{59} 82$ As mentioned previously, axin concentrations in cells are the lowest of all of the regulatory components and could therefore be rate limiting. ${ }^{49}$ However, Wnt signalling in mammalian cells does not appear to alter axinl protein concentrations (B Doble and J Woodgett, unpublished observation, 2004). These data suggest that the Wnt pathway may use multiple mechanisms to regulate the concentration of $\beta$ catenin, although the dominant mechanism appears to be via phosphorylation.

\section{DVL}

DVL binds to the C-terminal region of axin, which includes the DIX domain, and inhibits axin activation. ${ }^{83}$ The association of DVL with axin modulates the ability of axin to dimerise. DVL also binds CKI, which can promote Wnt3a mediated DVL phosphorylation. Phosphorylated DVL has a high affinity for Frat, which binds to and inhibits GSK3..$^{63} 84$ In Wnt stimulated cells, Frat bound to DVL might be able to prevent GSK3 bound to axin from phosphorylating $\beta$ catenin (fig 3A). Both DVL and axin have DIX domains that are necessary for the binding of DVL and axin to intracellular vesicles and actin filaments, which suggests that axin and DVL may regulate receptor mediated endocytosis of the Wnt signalling pathway. ${ }^{85}$ DVL also plays a role in relocating axin to the plasma membrane upon Wnt signalling. ${ }^{86}$ Studies on living embryos have confirmed previous findings that Wnt signals cause a relocalisation of axin from the cytoplasm to the plasma membrane and that this relocalisation is DVL dependent. ${ }^{59}$ 


\begin{tabular}{|c|c|c|c|c|}
\hline Tissue type & Exon/nt or aa & Position (aa) & Domain(s) affected & Ref \\
\hline CRC & 1 & S215L & APC-MEKK1? & 94 \\
\hline CRC & 1 & R103M & APC & 95 \\
\hline CRC & 1 & L101P & APC & 95 \\
\hline CRC & 3 & $\mathrm{R} 353 \mathrm{H}$ & GSK3 & 95 \\
\hline CRC & 1 & $\mathrm{~T} 122 \mathrm{~A}$ & APC & 95 \\
\hline CRC & 4 & E411D & GSK3 & 95 \\
\hline CRC & 4 & M418I & GSK3 & 95 \\
\hline CRC & 4 & R395C & GSK3 & 95 \\
\hline CRC & 5 & G584S & $\beta$ Catenin & 95 \\
\hline CRC & 2 & Y305X & MEKKI & 96 \\
\hline CRC & 1 & K203M & APC & 96 \\
\hline CRC & 2 & N307K & MEKKI & 96 \\
\hline CRC & 4 & $\mathrm{H} 394 \mathrm{~N}$ & GSK3 & 96 \\
\hline CRC & 10 & P848L & Axin-DVL & 96 \\
\hline CRC & 10 & E852G & Axin-DVL & 96 \\
\hline CRC & 1 & S215L & APC-MEKKI? & 94 \\
\hline$M B$ & $1-5$ (aa 89-528) & Del & APC-GSK3- $\beta$ catenin & 21 \\
\hline$M B$ & $1-5$ (a) $111-571)$ & Del & APC-GSK3- $\beta$ catenin & 21 \\
\hline$M B$ & $1-5$ (aa 59-532) & Del & APC-GSK3- $\beta$ catenin & 21 \\
\hline$M B$ & $9-10$ & Del & Axin-DVL & 21 \\
\hline$M B$ & $8-10$ & Del & Axin-DVL & 21 \\
\hline$M B$ & $6-10$ & Del & PP2A-axin-DIX & 21 \\
\hline$M B$ & $7-10$ & Del & PP2A-axin-DIX & 21 \\
\hline$M B$ & 1 & P255S & APC & 21 \\
\hline$M B$ & 1 & P255S & MEKKI & 20 \\
\hline$M B$ & 1 & S263C & MEKK1 & 20 \\
\hline $\mathrm{HCC}$ & 1 & Stop & APC-DVL-axin & 2 \\
\hline $\mathrm{HCC}$ & 4 & Stop & GSK3-DVL-axin & 2 \\
\hline $\mathrm{HCC}$ & 4 & $5 \mathrm{bp}$ del & $\beta$ Catenin & 2 \\
\hline $\mathrm{HCC}$ & 5 & $13 \mathrm{bp} \mathrm{del}$ & $\beta$ Catenin & 2 \\
\hline $\mathrm{HCC}$ & 3 & P345L & MEKKI & 97 \\
\hline $\mathrm{HCC}$ & 1 & L106R & APC & 97 \\
\hline $\mathrm{HCC}$ & 2 (1076 del 1 bp) & Frameshiff & MEKK1? & 97 \\
\hline $\mathrm{HCC}$ & 5 & Ins QVHH & $\beta$ Catenin-PP2A? & 97 \\
\hline $\mathrm{HCC}$ & 5 & G425S & $\beta$ Catenin & 97 \\
\hline$H B$ & 10 & $R 842 Q$ & Axin-DIX & 97 \\
\hline HB & 6 & G651S & PP2A? & 97 \\
\hline HB & 2 & T95M & APC & 98 \\
\hline EM & 4 & A397V & GSK3 & 99 \\
\hline SCC & 4 & G419A & GSK3 & 100 \\
\hline OEA & 4 & L416X & GSK3 & 101 \\
\hline ACC & 7 & P661L & PP2A & 102 \\
\hline ACC & 5 & G433E & $\beta$ Catenin & 102 \\
\hline ACC & 10 & E842K & Axin-DVL & 102 \\
\hline ACC & 10 & F824K & Axin-DVL & 102 \\
\hline ACC & 6 & S628Y & PP2A? & 102 \\
\hline \multicolumn{5}{|c|}{$\begin{array}{l}\text { Mutations found in the axinl coding sequence are scattered throughout the whole gene. There are some } \\
\text { differences between the alterations found in different forms of tumours. Large deletions are more common in } \\
\text { medulloblastomas, whereas missense mutations occur more frequently in hepatocellular carcinomas. Silent } \\
\text { mutations and polymorphisms reported in axin } 1 \text { are not included in this list. Protein and mRNA sequences are } \\
\text { based on Swissprot and GenBank accession numbers } 015169 \text { and AFO09674, respectively. } \\
\text { aa, amino acids; ACC, adenoid cystic carcinoma; APC, adenomatous polyposis coli; bp, base pair; CRC, } \\
\text { colorectal cancer; del, deletion; DVL, Dishevelled; EM, endometrial cancer; GSK3, glycogen synthase kinase 3; HB, } \\
\text { hepatoblastoma; HCC, hepatocellular cancer; MB, medulloblastomas; MEKK1, mitogen activated protein/ } \\
\text { extracellular regulated kinase kinase kinase 1; nt, nucleotide; OEA, ovarian endometrioid adenocarcinoma; PP2A, } \\
\text { protein phosphatase 2A; SCC, oesophageal squamous cell carcinoma. }\end{array}$} \\
\hline
\end{tabular}

\section{$\mathrm{CKI} / \mathrm{II}$}

CKI has recently been found to be an activator of Wnt signalling because microinjection of CKI into xenopus induces a secondary axis. ${ }^{87}$ The overexpression of CKI mimics Wnt signalling by stabilising $\beta$ catenin and thereby inducing the expression of $\beta$ catenin target genes. CKI has been detected in the axin-GSK3 complex and appears to phosphorylate APC and $\beta$ catenin (at Ser45) in an axin dependent manner. ${ }^{64} 7988 \mathrm{CKI}$ also competes for MEKKl binding and can attenuate axin-SAPK/JNK signalling. ${ }^{89}$ In contrast, although CKII also interacts with axin, it does not have an inhibitory effect on SAPK/JNK signalling..$^{89}$ CKII interacts and phosphorylates DVL, which is thought to inhibit the function of axin, thereby stimulating Wnt signal transduction. ${ }^{90}$

\section{PP2A}

PP2A is a broad specificity serine/threonine protein phosphatase that comprises a catalytic " $\mathrm{C}$ " subunit and various
" $\mathrm{A}$ " and " $\mathrm{B}$ " regulatory subunits that confer selective binding to proteins and scaffolds within cells. PP2A physically interacts with axin and APC in the axin-GSK3- $\beta$ catenin destruction complex and decreases the phosphorylation of axin, which suggests a positive role for PP2A in Wnt signal transduction. ${ }^{14}$ Phosphorylation of APC is also important for $\beta$ catenin binding and its subsequent degradation. PP2A has been implicated as a positive effector for Wnt mediated signalling. ${ }^{11}$ However, the phosphatase has other, confounding effects, probably because of it action on both positive and negative effectors of the pathway, such that its role is clearly complex. ${ }^{14} 659293$

\section{AXIN VARIANTS IN CANCER}

Alterations in both axinl and axin2 have been detected in several different tumours (tables 1 and 2). Mutations are found in most axin domains including the APC (RGS) and $\beta$ catenin binding domains. Axin sequence variants have also 
Table 2 Axin2 variants in human diseases

\begin{tabular}{llllr}
\hline Tissue type & Exon/nt (bp) & Position (aa) & $\begin{array}{c}\text { Domain } \\
\text { affected }\end{array}$ & Ref \\
\hline CRC & 7 & L688X & $?$ & 53 \\
CRC & 7 & E706X & $?$ & 53 \\
OEA & 7 & G665X & $?$ & 101 \\
CRC & 7 & E706Ter & $?$ & 103 \\
EM & 7 & S658C & $?$ & 99 \\
CRC/ & 7 & R656X & $?$ & 104 \\
Oligodentia & & & & \\
CRC/ & 7 (1995 ins G) & ?706X & $?$ & 104 \\
Oligodentia & 7 & R659W & $?$ & 97 \\
HCC & 7 & del TTPR & $?$ & 97 \\
HCC & 7 (2102; & & & \\
& del 12 bp) & &
\end{tabular}

Approximately $20 \%$ of mismatch repair deficient colorectal cancers harbour mutations in axin2. Most mutations are located around a $G_{7}$ repeat in exon 7 (nt 637-714), which results in premature protein truncation.

aa, amino acids; APC, adenomatous polyposis coli; bp, base pair; CRC, colorectal cancer; del, deletion; EM, endometrial cancer; GSK3, glycogen synthase kinase 3; HB, hepatoblastoma; HCC, hepatocellular cancer; ins, insertion; nt, nucleotide; OEA, ovarian endometrioid adenocarcinoma.

been found in colon, ovarian, endometrioid, adenocarcinoma, and HCC cell lines (table 3). Biochemical and functional studies have shown that these mutations interfere with the binding of GSK3 and that they also alter the interaction between axin and two upstream activators of TCF dependent transcription, Fratl and DVL. ${ }^{94}$ Several studies have investigated the role of axin in several types of tumour.

\section{Medulloblastoma}

Medulloblastoma (MB) is the most common malignant brain tumour in children. ${ }^{105}$ Most MBs are sporadic; however, patients with germline mutations in APC or PTCH (patched) genes carry a higher risk of this disease. ${ }^{106}$ In addition, mutations in $\beta$ catenin, another component in the Wnt pathway, have been detected in MB tumours. ${ }^{107-109}$ Recently, several deletions and single somatic point mutations in Axin l have been found in sporadic MB cases. ${ }^{20} 21110$ These aberrations include somatic point mutations, deletions, and loss of heterozygosity. The C-terminal deletion in these cases corresponded to loss of exons 6-10, where the DIX and oligomerisation domains are located. Oligomerisation of Axinl is crucial for the inhibition of TCF transcription, ${ }^{67}$ and $\mathrm{C}$-terminal deleted axinl fails to downregulate $\beta$ catenin and cell growth in the SW480 colon cancer cell line. ${ }^{63}$ Another type of inframe deletion that removes exons 1-5, the APC binding domain, has also been found in MB. The truncated protein lacks binding sites for APC, GSK3, and $\beta$ catenin (table 1). This mutant is also incapable of downregulating $\beta$ catenin. In addition, some truncated forms of axinl may act as dominant negatives and inactivate endogenous axinl. ${ }^{111}$

Table 3 Axin 1 variants identified in cancer cell lines

\begin{tabular}{lllllr}
\hline Cell line & Type & Exon & Position (aa) & $\begin{array}{l}\text { Domain(s) } \\
\text { affected }\end{array}$ & Ref \\
\hline MDAH- & OEA & 5 & V555I & $?$ & 101 \\
2774 & & & & & \\
SNU475 & HCC & $1-2$ & Del & APC & 2 \\
SNU423 & HCC & 3 & 13 bp del & GSK3 & 2 \\
Alexander & HCC & 4 & Del & GSK3 & 2 \\
HCT-8 & CRC & 4 & L396M & GSK3 & 94 \\
\hline
\end{tabular}

aa, amino acids; APC, adenomatous polyposis coli; bp, base pair; CRC, colorectal cancer; del, deletion; GSK3, glycogen synthase kinase 3; HCC, hepatocellular cancer; OEA, ovarian endometrioid adenocarcinoma.

\section{Colorectal cancer and familial tooth agenesis}

Many components of the Wnt signalling system are mutated in colorectal cancer. Germline loss of function mutations in the APC gene are associated with an inherited form of colorectal cancer-familial adenomatous polyposis-with 90-95\% penetrance. Somatic APC mutations are also found in most sporadic colorectal cancers. ${ }^{112}$ Alterations in other components of Wht signalling, including $\beta$ catenin, TCF, axin1, and axin2, found in colorectal cancer indicate the important role that this pathway plays in the aetiology of this disease. ${ }^{113}$ Most Axinl mutations in colorectal cancer occur between exon 1 and 5, where the APC, GSK3, and $\beta$ catenin binding domains are located (table 1). Mutations in axin2 have been found in approximately $20 \%$ of mismatch repair deficient colorectal tumours (table 2). ${ }^{6594101103}$ In most cases, one base deletion or insertion occurs in the mononucleotide repeat sequences located in exon 7 , leading to a frame shift and premature protein truncation. ${ }^{53}$ These mutations lead to elimination of the DIX domain, where DVL binds and negatively regulates axin activity. This domain is also essential for homo-oligomerisation of axin. The mutant form of axin2 appears to be more stable than the wild-type protein. Transfection of normal fibroblasts with axin 2 mutants led to the accumulation of $\beta$ catenin in the nuclei.

\section{"Alterations in other components of Wnt signalling, including $\beta$ catenin, TCF, axin 1, and axin2, found in colorectal cancer indicate the important role that this pathway plays in the aetiology of this disease"}

Immunohistochemical staining of $\beta$ catenin in tumours with defects in axin2 also showed nuclear accumulation of $\beta$ catenin in the cells. These results suggest a dominant negative effect of axin2 mutant proteins in cells. High levels of Axin2 gene expression have been detected in most human colon cancer cell lines (SW480, SW620, LoVo, SW620, Caco2, HT29, HCT116, T84, HCT15, and Alab), in addition to colorectal tumours. Axin2 appears to be a transcriptional target of the Wnt signalling pathway. Upregulation of Axin2 by Wnt- $\beta$ catenin appears to constitute a negative feedback loop that acts to restrain or desensitise Wnt signalling. Axin2 gene expression increases in response to raised concentrations of $\beta$ catenin, thereby modulating the duration and activity of the Wnt signal. ${ }^{47}{ }^{48}$ In addition to colorectal cancer, several Axin2 mutations have been found in patients with oligodentia. Linkage analysis of a Finnish family with colorectal cancer in association with oligodentia revealed a high logarithm of the odds score in chromosome 17 between markers D17S949 and D17S1352, where more than 80 known or predicted genes (including Axin2) are located. Direct mutational analysis of the coding sequence of Axin2 identified a base pair transition in exon 7, leading to premature termination of translation of Axin2, whereas family members with normal dentition showed no sign of Axin2 mutation or neoplasia. Axin2 is expressed in developing dental tissues, and germline Axin2 mutations found in patients with oligodentia provided the first evidence for its function. ${ }^{104}$ In a form of familial colorectal cancer, Gardner syndrome, the occurrence of odontomas and supernumerary teeth in association with familial adenomatous polyposis has been reported. ${ }^{114-117}$ These results indicate that overactivation of Wnt signalling as a result of mutation of a component of the $\beta$ catenin destruction complex, in addition to carcinogenesis, may lead to the failure of tooth development (tables 1-3).

\section{Hepatocellular carcinomas}

HCC and hepatoblastoma (HB) are primary liver cancers that occur predominantly in adults and children, respectively. 
Alteration of $\beta$ catenin occurs in approximately $20 \%$ of HCCs and $40-89 \%$ of HBs. ${ }^{23}{ }^{118-121}$ A fraction of HCCs $(\sim 10 \%)$ with wild-type $\beta$ catenin have mutations in Axinl or Axin2 instead. ${ }^{2}{ }^{122}$ These data suggest that alterations in the Wnt pathway are involved in the pathogenesis of a large proportion of both HBs and HCCs. The axinl mutations identified in the previous reports include truncation mutations as a result of either small deletion/insertion or nonsense mutations, although Axinl mutations found in liver cancer show a different spectrum of alterations. Most of the mutations found in these cases were predominantly missense. These Axin mutations apparently only affect one allele, so that their oncogenic effect may result from the dominant negative activity of the mutant Axin, which causes stabilisation of free $\beta$ catenin. ${ }^{16}$ In addition, detection of loss of heterozygosity at the Axinl locus suggests that axinl functions as a tumour suppressor. However, in a subset of tumours mutations in Axinl or Axin2 were found in addition to mutations in $\beta$ catenin. ${ }^{97}$ The expression of wild-type Axinl in HCC or colorectal cancer cells with APC, $\beta$ catenin, or Axinl mutations led to the induction of apoptosis. ${ }^{2}$ Even though axinl and axin2 are both able to downregulate $\beta$ catenin when overexpressed, and show similar biochemical characteristics, axin2 does not compensate for axinl mutations in HCCs. Therefore, axinl and axin2 expression is either cell type dependent or, more likely, these two proteins are not functionally equivalent.

\section{Ovarian endometrial adenocarcinomas}

Ovarian cancer is one of the most frequent gynaecological malignancies in women. ${ }^{123}$ A subtype of ovarian cancer, endometriosis, often shows defects in the components of the Wnt signalling pathway. Although mutations in APC are rare in this type of tumour, mutation of $\beta$ catenin is found in 16$24 \%$ of cases. ${ }^{24} 124125$ Recently, mutations in axinl and axin 2 have been detected in a subset of ovarian endometrial adenocarcinomas, where activation of TCF dependent transcription could be detected in a tumour with an Axin2 frameshift mutation (tables 1 and 2). As noted in cell lines, the mutated form of axin 2 appears to be more stable than the wild-type axin 2 protein. ${ }^{101}$

\section{Oesophageal squamous cell carcinoma}

Oesophageal cancer accounts for 7\% of all gastrointestinal malignancies, but in some regions of Asia its incidence may be as high as 170/100 000 of the population. About half of the oesophageal cancers diagnosed are squamous cell carcinomas (SCCs). Several studies suggest a role for defects in Wnt signalling in the pathogenesis of SCC. Deletion of chromosome 17 (where Axin2 is located) has been found in $45 \%$ of SCCs. ${ }^{126}$ Immunohistochemical studies of axinl have shown cytoplasmic localisation of the protein in normal stratified squamous epithelium of the oesophagus, whereas a mixed pattern of expression was detected in tumours. Protein expression analysis of seven oesophageal SSC cell lines revealed differential axin expression. Four cell lines (TEl, TE15, TT, and TTn) showed high expression, whereas another three cell lines (TE2, TE8 and TE13) showed very low axinl expression. However, northern blot analysis of the same cells showed similar amounts of RNA in all cases. Several mutations and polymorphisms have been reported in SCC tumours and cell lines (tables 1 and 3 ), and a correlation between reduced axinl expression and tumour progression has been suggested in oesophageal SCC..$^{100}{ }^{127}$

\section{Roles of axin/GSK3 in Alzheimer's disease}

In addition to tumorigenesis, defects in the Wnt signalling pathway have also been postulated to contribute to the pathogenesis of Alzheimer's disease (AD) ${ }^{128-130}$ The pathology of this form of dementia involves the deposition of amyloid plaques, which are made up of $\mathrm{A} \beta$ peptides derived from the abnormal cleavage of amyloid precursor protein, and neurofibrilliary tangles, which are composed of hyperphosphorylated forms of the microtubule associated protein, tau. These two lesions are associated with neuronal cell death. GSK3 is one of several protein kinases that phosphorylates tau at sites observed in the neurofibrilliary tangles. ${ }^{131-133}$ Axin negatively affects tau phosphorylation by GSK3. ${ }^{134}$ Tau that has been phosphorylated by GSK3 has a decreased capacity to bind and stabilise microtubules. ${ }^{135}$ Altered expression of PP2A, another protein implicated in Wnt signalling, has also been associated with $\mathrm{AD}$ pathology and appears to play a major role in regulating tau phosphorylation in the adult brain. ${ }^{136-139}$ These results have led to the hypothesis that deregulation of GSK3 might be involved in the pathogenesis of $\mathrm{AD} .{ }^{140}{ }^{141}$ Considering the central role that the scaffolding protein axin plays in regulating GSK3 mediated phosphorylation of $\beta$ catenin, and the fact that axin negatively regulates GSK3 mediated tau phosphorylation, it has been suggested that deregulation of the phosphorylation status of GSK3 may contribute to tau pathology in AD. A direct role for Wnt signalling in $\mathrm{AD}$ pathology remains to be demonstrated. However, it can be speculated that events leading to a decrease in GSK3-axin complex formation, and ultimately axin concentrations, may allow the aberrant phosphorylation of tau by GSK3 at primed sites that are increased in the $\mathrm{AD}$ brain, and thus contribute to tau dysfunction and pathology. ${ }^{142}$

\section{AXIN: A POTENTIAL TARGET FOR CANCER TREATMENT}

Given the clear link between defects in Wnt signalling components and several human cancers, compounds that either positively or negatively regulate these molecules according to their role in the pathway will provide valuable reagents for the development of anticancer drugs. Because axin positively regulates the SAPK/JNK (apoptosis) pathway and negatively regulates the Wnt (survival) pathway, and is the limiting factor in these systems, a search for axin antagonists or agonists might lead to the discovery of compounds that have potential for the treatment of cancer. To ascertain whether the Axin mutations found in cancers were biologically important, normal Axinl genes were inserted into the cancer cells and their effects on cell growth monitored. In the case of HCC cell lines, the introduction of Axin appeared to induce programmed cell death, suggesting a therapeutic potential. Although this opens up the possibility of using Axin as a cargo gene in gene therapy, small molecule approaches are also being pursued.

\section{"A search for axin antagonists or agonists might lead to the discovery of compounds that have potential for the treatment of cancer"}

The high frequency of mutations in the Wnt pathway in specific tumour types suggests that the activated transcriptional output of these pathways efficiently misregulates multiple growth regulatory functions. Because axin can degrade $\beta$ catenin when overexpressed in cells that lack functional APC it is a good candidate for cancer treatment. One drawback is that although the overexpression of axin l strongly promotes the downregulation of wild-type $\beta$ catenin in colon cancer cells, mutant, oncogenic $\beta$ catenin is unaffected.

Thus, Axin treatments would be selective for APC associated cancers. More studies of the mechanistic details of these molecules are required to elucidate the precise role and effect of axin stimulation in cancer treatment. 


\section{Take home messages}

- Axins (both Axin1 and its homologue Axin2) are tumour suppressor genes

- Deregulation of axin has been found in different forms of cancer

- Wnt signals modulate axin concentrations in the cell

- Axin is a rate limiting component of different signalling pathways

- The Wnt, stress activated protein kinase/Jun Nterminal kinase, and transforming growth factor $\beta$ signalling pathways are regulated by axin

- Upregulation of axin leads to the phosphorylation and degradation of $\beta$ catenin

- The overexpression of axin promotes apoptosis

\section{CONCLUDING REMARKS}

A large body of evidence indicates that the regulation of $\beta$ catenin stability and concentration in cells by the axinAPC-GSK3 complex is crucial for both embryogenesis and carcinogenesis. Axins act as negative regulators for Wnt signalling, and positive regulators for SAPK/JNK signalling. Because axin itself is sensitive to Wnt signals, axin concentrations in cells fluctuate, which probably impacts upon its other functions. Despite being discovered in 1997, there is much to be learned about the physiological functions and roles of axin. In common with several other molecules in the Wnt signalling pathways, axin binds to different components and regulates opposite functions in the cell. The question is how axin operates to maintain the specificity of these different signalling pathways. Downregulation of axin can be just as catastrophic as too much activity. Axin2 overexpression in cells leads to apoptosis, yet upregulation of axin2 is found in most colorectal cancers. Deregulation of axin2 can be detected in adenomas where cells do not show $\beta$ catenin nuclear accumulation, which indicates that axin2 might be an early marker of tumour initiation. Furthermore, axin2 is mostly located in the nucleus, and has access to the "active" form of its target molecule, $\beta$ catenin. It remains to be determined how the basal concentrations of axins are controlled and how their nuclear and cytoplasmic localisation is accomplished. Currently, our understanding of axins suggests that these proteins play key assembly functions for promoting efficient protein-protein interaction and stand at the crossroads of several signalling paths-helping to integrate and coordinate the plethora of continuously changing signals.

\section{ACKNOWLEDGEMENTS}

Supported by grants from the Canadian Institutes of Health Research and the National Institute of Cancer/Canadian Cancer Society.

\section{Authors' affiliations}

S Salahshor, J R Woodgett, Ontario Cancer Institute, Division of Experimental Therapeutics, Toronto, Ontario, Canada, M5G 2M9

\section{APPENDIX 1 ONLINE LINKS AND DATABASES}

- http://kinase.uhnres.utoronto.ca/Sima/axins_pathway/ (Axin page)

- http://www.stanford.edu/ rnusse/wntwindow.html (Wnt page)

- http://us.expasy.org/prosite/ (Prosite database)

\section{REFERENCES}

1 Zeng L, Fagotto F, Zhang T, et al. The mouse Fused locus encodes axin, an inhibitor of the Wnt signalling pathway that regulates embryonic axis formation. Cell 1997;90:181-92.

2 Satoh S, Daigo Y, Furukawa Y, et al. AXIN1 mutations in hepatocellular carcinomas, and growth suppression in cancer cells by virus-mediated transfer of AXIN1. Nat Genet 2000;24:245-50.

3 Akiyama T. Wnt/beta-catenin signaling. Cytokine Growth Factor Rev 2000;11:273-82.

4 Wodarz A, Nusse, R. Mechanisms of Wnt signaling in development. Annu Rev Cell Dev Biol 1998; 14:59-88.

5 Bienz M, Clevers H. Linking colorectal cancer to Wnt signaling. Cell 2000; 103:311-20.

6 Bellamy CO, Malcomson RD, Harrison DJ, et al. Cell death in health and disease: the biology and regulation of apoptosis. Semin Cancer Biol 1995;6:3-16.

7 Molenaar $M$, van de Wetering $M$, Oosterwegel $M$, et al. XTcf-3 transcription factor mediates beta-catenin-induced axis formation in Xenopus embryos. Cell 1996;86:391-9.

8 Behrens J, von Kries JP, Kuhl M, et al. Functional interaction of beta-catenin with the transcription factor LEF-1. Nature 1996;382:638-42.

9 He TC, Sparks AB, Rago C, et al. Identification of c-MYC as a target of the APC pathway. Science 1998;281:1509-12.

10 Tetsu O, McCormick F. $\beta$-Catenin regulates expression of cyclin D1 in colon carcinoma cells. Nature 1999;398:422-6.

11 Shutman M, Zhurinsky J, Simcha I, et al. The cyclin D1 gene is a target of the beta-catenin/LEF-1 pathway. Proc Natl Acad Sci U S A 1999;96:5522-7.

12 Ikeda S, Kishida S, Yamamoto H, et al. Axin, a negative regulator of the Wnt signaling pathway, forms a complex with GSK-3beta and beta-catenin and promotes GSK-3beta-dependent phosphorylation of beta-catenin. EMBO J 1998;17:1371-84.

13 Kishida S, Yamamoto H, lkeda S, et al. Axin, a negative regulator of the wnt signaling pathway, directly interacts with adenomatous polyposis coli and regulates the stabilization of beta-catenin. J Biol Chem 1998;273:10823-6.

14 Ikeda S, Kishida M, Matsuura Y, et al. GSK-3beta-dependent phosphorylation of adenomatous polyposis coli gene product can be modulated by beta-catenin and protein phosphatase 2A complexed with axin. Oncogene 2000;19:537-45.

15 Morin PJ. Beta-catenin signaling and cancer. Bioessays 1999;21:1021-30.

16 Behrens J, Jerchow BA, Wurtele $M$, et al. Functional interaction of an axin homolog, conductin, with beta-catenin, APC, and GSK3beta. Science 1998;280:596-9.

17 Kinzler KW, Nilbert MC, Vogelstein B, et al. Identification of a gene located at chromosome 5q21 that is mutated in colorectal cancers. Science $1991 ; 251: 1366-70$.

18 Morin PJ, Sparks AB, Korinek V, et al. Activation of beta-catenin-Tcf signaling in colon cancer by mutations in beta-catenin or APC. Science 1997;275:1787-90.

19 llyas M, Tomlinson IP, Novelli MR, et al. Clinico-pathological features and p53 expression in left-sided sporadic colorectal cancers with and without microsatellite instability. J Pathol 1996;179:370-5.

20 Baeza N, Masuoka J, Kleihues $\mathrm{P}$, et al. AXINI mutations but not deletions in cerebellar medulloblastomas. Oncogene 2003;22:632-6.

21 Dahmen RP, Koch A, Denkhaus D, et al. Deletions of AXIN1, a component of the WNT/wingless pathway, in sporadic medulloblastomas. Cancer Res 2001;61:7039-43.

22 Rubinfeld B, Robbins P, El-Gamil M, et al. Stabilization of beta-catenin by genetic defects in melanoma cell lines. Science 1997;275:1790-2.

23 Miyoshi Y, Iwao K, Nagasawa Y, et al. Activation of the beta-catenin gene in primary hepatocellular carcinomas by somatic alterations involving exon 3 . Cancer Res 1998:58:2524-7.

24 Palacios J, Gamallo C. Mutations in the beta-catenin gene (CTNNB1) in endometrioid ovarian carcinomas. Cancer Res 1998;58:1344-7.

25 Fukuchi T, Sakamoto $M$, Tsuda $\mathrm{H}$, et al. Beta-catenin mutation in carcinoma of the uterine endometrium. Cancer Res 1998;58:3526-8.

26 Polakis P. Wnt signaling and cancer. Genes Dev 2000;14:1837-51.

27 Willert K, Shibamoto S, Nusse R. Wnt-induced dephosphorylation of axin releases beta-catenin from the axin complex. Genes Dev 1999;13:1768-73.

28 Massague J. TGF-beta signal transduction. Annu Rev Biochem 1998;67:753-91.

29 Heldin CH, Miyazono K, ten Dijke P. TGF-beta signalling from cell membrane to nucleus through SMAD proteins. Nature 1997;390:465-71.

30 Chakrabarty S, Fan D, Varani J. Modulation of differentiation and proliferation in human colon carcinoma cells by transforming growth factor beta 1 and beta 2. Int J Cancer 1990;46:493-9.

31 Jass JR, Do KA, Simms LA, et al. Morphology of sporadic colorectal cancer with DNA replication errors. Gut 1998;42:673-9.

32 Furuhashi M, Yagi K, Yamamoto H, et al. Axin facilitates Smad3 activation in the transforming growth factor beta signaling pathway. Mol Cell Biol $2001 ; 21: 5132-41$.

33 Nishita M, Hashimoto MK, Ogata S, et al. Interaction between Wnt and TGF-beta signalling pathways during formation of Spemann's organizer. Nature 2000;403:781-5.

34 Ip YT, Davis RJ. Signal transduction by the c-Jun N-terminal kinase (JNK)from inflammation to development. Curr Opin Cell Biol 1998;10:205-19.

35 Leppa S, Bohmann D. Diverse functions of JNK signaling and c-Jun in stress response and apoptosis. Oncogene 1999;18:6158-62.

36 Schaeffer HJ, Weber MJ. Mitogen-activated protein kinases: specific messages from ubiquitous messengers. Mol Cell Biol 1999;19:2435-44. 
37 Zhang Y, Neo SY, Wang X, et al. Axin forms a complex with MEKK1 and activates $\mathrm{C}$-Jun $\mathrm{NH}(2)$-terminal kinase/stress-activated protein kinase through domains distinct from Wnt signaling. J Biol Chem 1999;274:35247-54.

38 Zhang Y, Neo SY, Han J, et al. Dimerization choices control the ability of axin and dishevelled to activate c-Jun $\mathrm{N}$-terminal kinase/stress-activated protein kinase. J Biol Chem 2000;275:25008-14.

39 Neo SY, Zhang Y, Yaw LP, et al. Axin-induced apoptosis depends on the extent of its JNK activation and its ability to down-regulate beta-catenin levels. Biochem Biophys Res Commun 2000;272:144-50.

40 Clevers H. Axin and hepatocellular carcinomas. Nat Genet 2000;24:206-8.

41 Aaltonen LA. Hereditary intestinal cancer. Semin Cancer Biol 2000; 10:289-98.

42 Hsu W, Shakya R, Costantini F. Impaired mammary gland and lymphoid development caused by inducible expression of Axin in transgenic mice. J Cell Biol 2001;155:1055-64.

43 Hoeflich KP, Luo J, Rubie EA, et al. Requirement for glycogen synthase kinase-3beta in cell survival and NF-kappaB activation. Nature 2000;406:86-90.

44 Zhang Y, Qiu WJ, Liu DX, et al. Differential molecular assemblies underlie the dual function of Axin in modulating the WNT and JNK pathways. J Biol Chem 2001;276:32152-9.

45 Luo W, Lin SC. Axin: a master scaffold for multiple signaling pathways. Neurosignals 2004;13:99-113.

46 Luo W, Ng WW, Jin LH, et al. Axin utilizes distinct regions for competitive MEKK 1 and MEKK 4 binding and JNK activation. J Biol Chem 2003;278:37451-8

47 Lustig B, Jerchow B, Sachs M, et al. Negative feedback loop of Wnt signaling through upregulation of conductin/axin2 in colorectal and liver tumors. Mol Cell Biol 2002;22:1 184-93.

48 Yan D, Wiesmann M, Rohan M, et al. Elevated expression of axin2 and hnkd mRNA provides evidence that $\mathrm{Wnt} /$ beta-catenin signaling is activated in human colon tumors. Proc Natl Acad Sci U S A 2001:98:14973-8.

49 Lee E, Salic A, Kruger R, et al. The roles of APC and axin derived from experimental and theoretical analysis of the Wnt pathway. PLoS Biol 2003:E10.

50 Cong F, Varmus H. Nuclear-cytoplasmic shuttling of Axin regulates subcellular localization of beta-catenin. Proc Natl Acad Sci U S A 2004; 101:2882-7

51 Yamamoto H, Kishida S, Uochi T, et al. Axil, a member of the Axin family, interacts with both glycogen synthase kinase 3 beta and beta-catenin and inhibits axis formation of Xenopus embryos. Mol Cell Biol 1998; 18:2867-75.

52 Mai M, Qian C, Yokomizo A, et al. Cloning of the human homolog of conductin (AXIN2), a gene mapping to chromosome 17q23-q24. Genomics 1999:55:341-4.

53 Liu W, Dong X, Mai M, et al. Mutations in AXIN2 cause colorectal cancer with defective mismatch repair by activating beta-catenin/TCF signalling Nat Genet 2000;26:146-7.

54 Dong X, Seelan RS, Qian C, et al. Genomic structure, chromosome mapping and expression analysis of the human AXIN2 gene. Cytogenet Cell Genet $2001 ; 93: 26-8$

55 Anderson CB, Neufeld KL, White RL. Subcellular distribution of Wnt pathway proteins in normal and neoplastic colon. Proc Natl Acad Sci U S A 2002:99:8683-8.

56 Wiechens N, Heinle K, Englmeier L, et al. Nucleo-cytoplasmic shuttling of Axin, a negative regulator of the Wnt-beta-catenin pathway. J Biol Chem 2004;279:5263-7

57 Wehrli M, Dougan ST, Caldwell K, et al. Arrow encodes an LDL-receptorrelated protein essential for Wingless signalling. Nature 2000:407:527-30.

58 Mao J, Wang J, Liu B, et al. Low-density lipoprotein receptor-related protein5 binds to Axin and regulates the canonical Wnt signaling pathway. Mol Cell 2001;7:801-9.

59 Tolwinski NS, Wehrli $M$, Rives A, et al. Wg/Wnt signal can be transmitted through arrow/LRP5,6 and Axin independently of Zw3/Gsk3beta activity. Dev Cell 2003;4:407-18

60 Li L, Yuan H, Weaver CD, et al. Axin and Fratl interact with dvl and GSK, bridging Dvl to GSK in Wnt-mediated regulation of LEF-1. EMBO J 1999; 18:4233-40

61 Hart MJ, de los Santos R, Albert IN, et al. Downregulation of beta-catenin by human Axin and its association with the APC tumor suppressor, beta-catenin and GSK3 beta. Curr Biol 1998;8:573-81.

62 Nakamura T, Hamada F, Ishidate T, et al. Axin, an inhibitor of the Wnt signalling pathway, interacts with beta-catenin, GSK-3beta and APC and reduces the beta-catenin level. Genes Cells 1998;3:395-403.

63 Kishida S, Yamamoto H, Hino S, et al. DIX domains of Dvl and axin are necessary for protein interactions and their ability to regulate beta-catenin stability. Mol Cell Biol 1999;19:4414-22.

64 Rubinfeld B, Tice DA, Polakis P. Axin-dependent phosphorylation of the adenomatous polyposis coli protein mediated by casein kinase lepsilon. J Biol Chem 2001;276:39037-45.

65 Hsu W, Zeng L, Costantini F. Identification of a domain of axin that binds to the serine/threonine protein phosphatase $2 \mathrm{~A}$ and a self-binding domain. J Biol Chem 1999;274:3439-45.

66 Farr GH 3rd, Ferkey DM, Yost C, et al. Interaction among GSK-3, GBP, axin, and APC in Xenopus axis specification. J Cell Biol 2000;148:691-702.

67 Sakanaka C, Williams LT. Functional domains of axin. Importance of the C terminus as an oligomerization domain. J Biol Chem 1999:274:14090-3.

68 Nakamura Y, Nishisho I, Kinzler KW, et al. Mutations of the APC (adenomatous polyposis coli) gene in FAP (familial polyposis coli) patients and in sporadic colorectal tumors. Tohoku J Exp Med 1992;168:141-7.
69 Salic A, Lee E, Mayer L, et al. Control of beta-catenin stability: reconstitution of the cytoplasmic steps of the wnt pathway in Xenopus egg extracts. Mol Cell 2000;5:523-32.

70 Polakis $\mathbf{P}$. The adenomatous polyposis coli (APC) tumor suppressor. Biochim Biophys Acta 1997;1332:F127-47.

71 von Kries JP, Winbeck G, Asbrand C, et al. Hot spots in beta-catenin for interactions with LEF-1, conductin and APC. Nat Struct Biol 2000;7:800-7.

72 Matsuzawa SI, Reed JC. Siah-1, SIP, and Ebi collaborate in a novel pathway for beta-catenin degradation linked to $\mathrm{p} 53$ responses. Mol Cell 2001;7:915-26.

73 Liu J, Stevens J, Rote CA, et al. Siah-1 mediates a novel beta-catenin degradation pathway linking p53 to the adenomatous polyposis coli protein. Mol Cell 2001;7:927-36.

74 Levina E, Oren M, Ben-Ze'ev A. Downregulation of beta-catenin by p53 involves changes in the rate of beta-catenin phosphorylation and Axin dynamics. Oncogene 2004;23:4444-53.

75 Woodgett JR. Judging a protein by more than its name: GSK-3. Sci STKE 2001; 100:RE12.

76 Doble BW, Woodgett JR. GSK-3: tricks of the trade for a multi-tasking kinase. J Cell Sci 2003;1 16:1175-86.

77 Hedgepeth CM, Deardorff MA, Rankin K, et al. Regulation of glycogen synthase kinase 3 beta and downstream Wnt signaling by axin. Mol Cell Biol 1999; 19:7147-57.

78 Hinoi T, Yamamoto H, Kishida M, et al. Complex formation of adenomatous polyposis coli gene product and axin facilitates glycogen synthase kinase-3 beta-dependent phosphorylation of beta-catenin and down-regulates betacatenin. J Biol Chem 2000;275:34399-406.

79 Amit S, Hatzubai A, Birman Y, et al. Axin-mediated CKI phosphorylation of beta-catenin at Ser 45: a molecular switch for the Wnt pathway. Genes Dev 2002; 16:1066-76.

80 Yamamoto $\mathrm{H}$, Kishida S, Kishida $M$, et al. Phosphorylation of axin, a Wnt signal negative regulator, by glycogen synthase kinase-3beta regulates its stability. J Biol Chem 1999;274:10681-4.

81 Jho E, Lomvardas S, Costantini F. A GSK3beta phosphorylation site in axin modulates interaction with beta-catenin and Tcf-mediated gene expression. Biochem Biophys Res Commun 1999;266:28-35.

82 Tolwinski NS, Wieschaus E. Rethinking WNT signaling. Trends Genet 2004;20:177-81.

83 Julius MA, Schelbert B, Hsu W, et al. Domains of axin and disheveled required for interaction and function in wnt signaling. Biochem Biophys Res Commun 2000;276:1 162-9.

84 Kishida M, Hino Si, Michive T, et al. Synergistic activation of the Wnt signaling pathway by Dvl and casein kinase lepsilon. J Biol Chem 2001;276:33147-55.

85 Capelluto DG, Kutateladze TG, Habas R, et al. The DIX domain targets dishevelled to actin stress fibres and vesicular membranes. Nature 2002;419:726-9.

86 Cliffe A, Hamada F, Bienz M. A role of Dishevelled in relocating Axin to the plasma membrane during wingless signaling. Curr Biol 2003;13:960-6.

87 Peters JM, McKay RM, McKay JP, et al. Casein kinase I transduces Wnt signals. Nature 1999;401:345-50.

88 Sakanaka C, Leong $\mathrm{P}, \mathrm{Xu}$ L, et al. Casein kinase iepsilon in the wnt pathway: regulation of beta-catenin function. Proc Natl Acad Sci U S A 1999;96:12548-52.

89 Zhang Y, Qiu WJ, Chan SC, et al. Casein kinase I and casein kinase II differentially regulate axin function in Wnt and JNK pathways. J Biol Chem 2002;277:17706-12.

90 Willert K, Brink M, Wodarz A, et al. Casein kinase 2 associates with and phosphorylates dishevelled. EMBO J 1997;16:3089-96.

91 Ratcliffe MJ, Itoh K, Sokol SY. A positive role for the PP2A catalytic subunit in Wnt signal transduction. J Biol Chem 2000;275:35680-3.

92 Seeling JM, Miller JR, Gil R, et al. Regulation of beta-catenin signaling by the B56 subunit of protein phosphatase 2A. Science 1999;283:2089-91.

93 Li X, Yost HJ, Virshup DM, et al. Protein phosphatase 2A and its B56 regulatory subunit inhibit Wnt signaling in Xenopus. EMBO J 2001;20:4122-31.

94 Webster MT, Rozycka M, Sara E, et al. Sequence variants of the axin gene in breast, colon, and other cancers: an analysis of mutations that interfere with GSK3 binding. Genes Chromosomes Cancer 2000;28:443-53.

95 Shimizu Y, lkeda S, Fujimori $M$, et al. Frequent alterations in the Wnt signaling pathway in colorectal cancer with microsatellite instability. Genes Chromosomes Cancer 2002;33:73-81.

96 Jin LH, Shao QJ, Luo W, et al. Detection of point mutations of the Axin 1 gene in colorectal cancers. Int J Cancer 2003;107:696-9.

97 Taniguchi K, Roberts LR, Aderca IN, et al. Mutational spectrum of betacatenin, AXIN1, and AXIN2 in hepatocellular carcinomas and hepatoblastomas. Oncogene 2002;21:4863-71.

98 Miao J, Kusafuka T, Udatsu Y, et al. Sequence variants of the Axin gene in hepatoblastoma. Hepatol Res 2003;25:174-179.

99 Moreno-Bueno G, Hardisson D, Sanchez C, et al. Abnormalities of the APC/ beta-catenin pathway in endometrial cancer. Oncogene 2002;21:7981-90.

100 Nakajima M, Fukuchi M, Miyazaki T, et al. Reduced expression of Axin correlates with tumour progression of oesophageal squamous cell carcinoma. Br J Cancer 2003;88:1734-9.

101 Wu R, Zhai Y, Fearon ER, et al. Diverse mechanisms of beta-catenin deregulation in ovarian endometrioid adenocarcinomas. Cancer Res 2001;61:8247-55.

102 Daa T, Kashima K, Kaku N, et al. Mutations in components of the Wnt signaling pathway in adenoid cystic carcinoma. Mod Pathol 2004;17:1475-82. 
103 Domingo $E$, Espin $E$, Armengol $M$, et al. Activated BRAF targets proximal colon tumors with mismatch repair deficiency and MLH1 inactivation. Genes Chromosomes Cancer 2004;39:138-42.

104 Lammi L, Arte S, Somer M, et al. Mutations in AXIN2 cause familial tooth agenesis and predispose to colorectal cancer. Am J Hum Genet 2004; 74:1043-50.

105 Stevens MC, Cameron AH, Muir KR, et al. Descriptive epidemiology of primary central nervous system tumours in children: a population-based study. Clin Oncol (R Coll Radiol) 1991;3:323-9.

106 Hamilton SR, Liu B, Parsons RE, et al. The molecular basis of Turcot's syndrome. N Engl J Med 1995;332:839-47.

107 Zurawel RH, Chiappa SA, Allen C, et al. Sporadic medulloblastomas contain oncogenic beta-catenin mutations. Cancer Res 1998;58:896-9.

108 Eberhart CG, Tihan T, Burger PC. Nuclear localization and mutation of betacatenin in medulloblastomas. J Neuropathol Exp Neurol 2000:59:333-7.

109 Huang H, Mahler-Araujo BM, et al. APC mutations in sporadic medulloblastomas. Am J Pathol 2000;156:433-7.

110 Yokota N, Nishizawa S, Ohta S, et al. Role of Wnt pathway in medulloblastoma oncogenesis. Int J Cancer 2002;101:198-201.

111 Fagotto $F$, Jho E, Zeng L, et al. Domains of axin involved in protein-protein interactions, Wnt pathway inhibition, and intracellular localization. $J$ Cell Biol 1999; 145:741-56.

112 Kinzler KW, Vogelstein B. Lessons from hereditary colorectal cancer. Cell 1996:87:159-70.

113 Lustig B, Behrens J. The Wnt signaling pathway and its role in tumor development. J Cancer Res Clin Oncol 2003;129:199-221.

114 Gardner E. Follow-up study of a family group exhibiting dominant inheritance for a syndrome including intestinal polyps, osteomas, fibromas and epidermal cysts. Am J Hum Genet 1962;14:376-90.

115 Ida M, Nakamura T, Utsunomiya J. Osteomatous changes and tooth abnormalities found in the jaw of patients with adenomatosis coli. Oral Surg Oral Med Oral Pathol 1981;52:2-11.

116 Carl W, Sullivan MA. Dental abnormalities and bone lesions associated with familial adenomatous polyposis: report of cases. J Am Dent Assoc 1989;119:137-9.

117 Aggarwal VR, Sloan P, Horner K, et al. Dento-osseous changes as diagnostic markers in familial adenomatous polyposis families. Oral Dis 2003;9:29-33.

118 de La Coste A, Romagnolo B, Billuart $P$, et al. Somatic mutations of the betacatenin gene are frequent in mouse and human hepatocellular carcinomas. Proc Natl Acad Sci U S A 1998;95:8847-51

119 Kondo Y, Kanai Y, Sakamoto M, et al. Beta-catenin accumulation and mutation of exon 3 of the beta-catenin gene in hepatocellular carcinoma. Jpn J Cancer Res 1999;90:1301-9.

120 Ihara A, Koizumi H, Hashizume R, et al. Expression of epithelial cadherin and alpha- and beta-catenins in nontumoral livers and hepatocellular carcinomas. Hepatology 1996;23:1441-7.

121 Huang $H$, Fujii $H$, Sankila $A$, et al. Beta-catenin mutations are frequent in human hepatocellular carcinomas associated with hepatitis $C$ virus infection. Am J Pathol 1999;155:1795-801.

122 Laurent-Puig P, Legoix P, Bluteau O, et al. Genetic alterations associated with hepatocellular carcinomas define distinct pathways of hepatocarcinogenesis. Gastroenterology 2001;120:1763-73.

123 Greenlee RT, Hill-Harmon MB, Murray T, et al. Cancer statistics, 2001. CA Cancer J Clin 2001;51:15-36.

124 Saegusa M, Okayasu I. Frequent nuclear beta-catenin accumulation and associated mutations in endometrioid-type endometrial and ovarian carcinomas with squamous differentiation. J Pathol 2001;194:59-67.
125 Wright K, Wilson P, Morland S, et al. Beta-catenin mutation and expression analysis in ovarian cancer: exon 3 mutations and nuclear translocation in $16 \%$ of endometrioid tumours. Int J Cancer 1999;82:625-9.

126 Wagata T, Ishizaki K, Imamura M, et al. Deletion of $17 \mathrm{p}$ and amplification of the int-2 gene in esophageal carcinomas. Cancer Res 1991;51:2113-17.

127 de Castro J, Gamallo C, Palacios J, et al. Beta-catenin expression pattern in primary oesophageal squamous cell carcinoma. Relationship with clinicopathologic features and clinical outcome. Virchows Arch 2000;437:599-604

128 Kang DE, Soriano S, Xia X, et al. Presenilin couples the paired phosphorylation of beta-catenin independent of axin: implications for betacatenin activation in tumorigenesis. Cell 2002;110:751-62.

129 De Ferrari GV, Chacon MA, Barria Ml, et al. Activation of Wnt signaling rescues neurodegeneration and behavioral impairments induced by betaamyloid fibrils. Mol Psychiatry 2003;8:195-208.

130 De Strooper B, Woodgett J. Alzheimer's disease: mental plaque removal. Nature 2003:423:392-3.

131 Hanger DP, Hughes K, Woodgett JR, et al. Glycogen synthase kinase-3 induces Alzheimer's disease-like phosphorylation of tau: generation of paired helical filament epitopes and neuronal localisation of the kinase. Neurosci Lett 1992;147:58-62.

132 Ishiguro K, Shiratsuchi A, Sato S, et al. Glycogen synthase kinase 3 beta is identical to tau protein kinase I generating several epitopes of paired helical filaments. FEBS Lett 1993;325:167-72.

133 Lovestone S, Reynolds CH, Latimer D, et al. Alzheimer's disease-like phosphorylation of the microtubule-associated protein tau by glycogen synthase kinase- 3 in transfected mammalian cells. Curr Biol synthase kinase-3

134 Stoothoff WH, Bailey CD, Mi K, et al. Axin negatively affects tau phosphorylation by glycogen synthase kinase 3beta. J Neurochem 2002;83:904-13.

135 Spittaels K, Van den Haute C, Van Dorpe J, et al. Glycogen synthase kinase3beta phosphorylates protein tau and rescues the axonopathy in the central nervous system of human four-repeat tau transgenic mice. J Biol Chem 2000;275:41340-9.

136 Sontag E, Luangpirom A, Hladik C, et al. Altered expression levels of the protein phosphatase $2 \mathrm{~A}$ ABalphaC enzyme are associated with Alzheimer disease pathology. J Neuropathol Exp Neurol 2004;63:287-301.

137 Planel E, Miyasaka T, Launey T, et al. Alterations in glucose metabolism induce hypothermia leading to tau hyperphosphorylation through differential inhibition of kinase and phosphatase activities: implications for Alzheimer's disease. J Neurosci 2004;24:2401-11.

138 Kins S, Kurosinski P, Nitsch RM, et al. Activation of the ERK and JNK signaling pathways caused by neuron-specific inhibition of PP2A in transgenic mice. Am J Pathol 2003;163:833-43.

139 Sun L, Liu SY, Zhou XW, et al. Inhibition of protein phosphatase 2Aand protein phosphatase 1-induced tau hyperphosphorylation and impairment of spatial memory retention in rats. Neuroscience 2003; 118:1175-82.

140 Sperber BR, Leight S, Goedert M, et al. Glycogen synthase kinase-3 beta phosphorylates tau protein at multiple sites in intact cells. Neurosci Lett 1995; 197:149-53.

141 Flaherty DB, Soria JP, Tomasiewicz HG, et al. Phosphorylation of human tau protein by microtubule-associated kinases: GSK3beta and cdk5 are key participants. J Neurosci Res 2000;62:463-72.

142 Goedert M, Strittmatter WJ, Roses AD. Alzheimer's disease. Risky apolipoprotein in brain. Nature 1994;372:45-6. 


\section{PostScript}

\section{CORRESPONDENCE}

\section{Poorly differentiated hepatocellular carcinoma with unusual tubular structures}

The patient was a 70 year old woman. A tumour in liver segment 8 arose in a background of cirrhotic liver with chronic hepatitis $C$ and reached a size of $6.0 \mathrm{~cm}$ in six months. The patient's serum concentration was raised $(17101 \mathrm{ng} / \mathrm{ml})$, and the tumour was suspected to be hepatocellular carcinoma (HCC) based on various image findings. An extended liver anterior segmentectomy was performed, and serum $\alpha$ fetoprotein returned to normal immediately after surgery.

Although the macroscopic findings were compatible with conventional HCC (fig 1A), the histology of the tumour was atypical-the tumour cells mainly formed irregular tubular structures filled with a bloody/serous or bloody fluid (fig 1B), and small tubular or acinar-like structures were also found (fig 1C). Solid structures were seen in a small portion of the tumour (fig ID), and massive bleeding was also seen. The tumour cells had abundant eosinophilic granular cytoplasm and round nuclei with moderate variations in size and shape. The typical trabecular pattern was not seen, and no evidence of desmoplastic stroma, extracapsular proliferation, vascular invasion, or Alcian blue/periodic acid Schiff positive mucin was
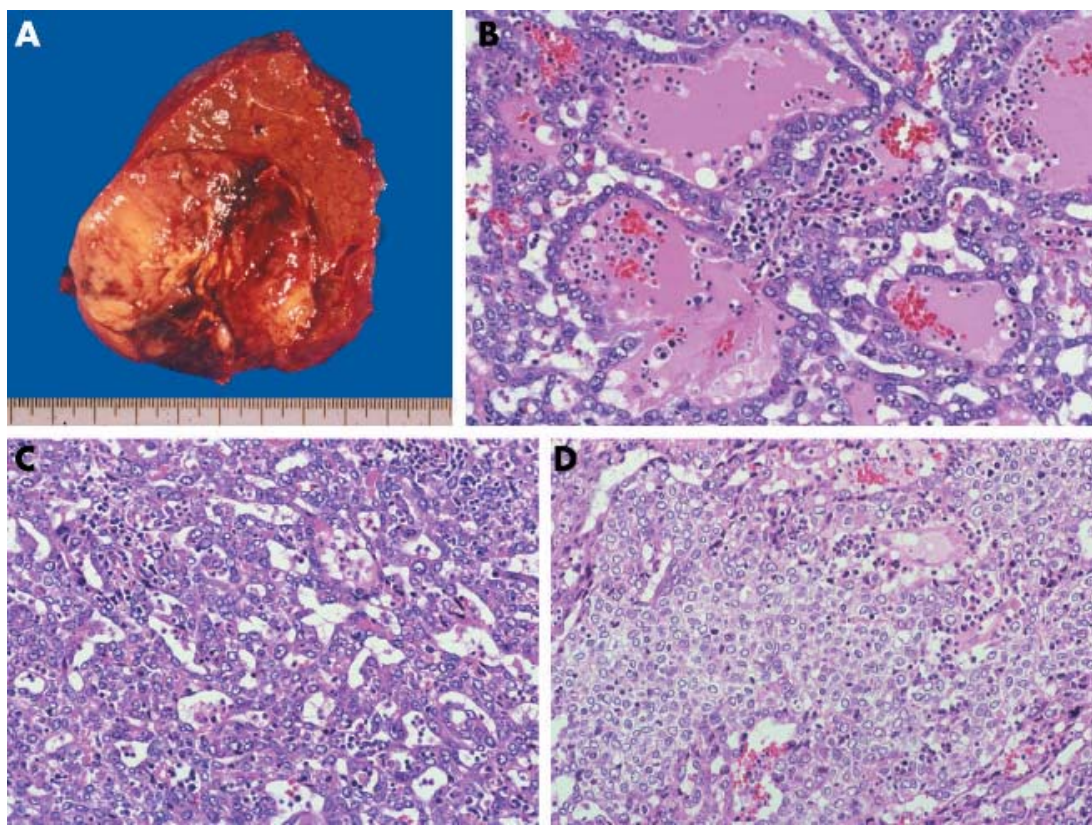

Figure 1 (A) Macroscopically, the nodular S8 tumour has a fibrous capsule. The cut surface of the tumour is well circumscribed, expanded, and yellow/white to dark red in colour. (B) The tumour cells have abundant eosinophilic granular cytoplasm and round nuclei with moderate variations in size and shape. The irregular trabecular structures are filled with a bloody/serous or bloody fluid without mucin production and desmoplastic tissue. The typical trabecular pattern was not seen (haematoxylin and eosin (H\&E) stain, original magnification, $\times 200)$. (C) Small tubular or acinarlike patterns are also visible (H\&E stain; original magnification, $\times 200)$. (D) Solid structures are seen in a small portion of the tumour (H\&E stain; original magnification, $\times 200)$. desmoplastic stroma were not compatible with these types of tumours.

The reticular-like pattern suggested a yolk sac tumour, and an association between hepatitis $\mathrm{C}$ virus infection and yolk sac tumours has been suggested. ${ }^{3}$ However, specific features, such as Schiller-Duval bodies, a cystic pattern, and hyaline globules, were not detected. In addition, the tumour was immunohistochemically negative for $2 \mathrm{~A} 2,2 \mathrm{Gl0}$, and 4C4, which have been reported to be specific to yolk sac tumours.

A strong reactivity for vimentin is associated with metastatic HCCs or sarcomatous $\mathrm{HCCs}^{45}$ indicating a highly malignant form of HCC. Clinically, this tumour showed rapid growth and a high proliferative activity of $60 \%$ as assessed by the MIB- 1 labelling index.

Considering the various findings described above, we finally diagnosed this tumour as an unusual type of HCC with poorly differentiated features presenting with a high degree of malignancy. Thirteen months after surgery, a new tumour was detected in liver segment 2 and percutaneous ethanol injection therapy was performed.

J Yamaguchi

Clinical Laboratory Division, National Cancer Centre Hospital, Tokyo, Japan

H Ojima, N Hiraoka

Pathology Division, National Cancer Centre Research Institute, Tokyo, Japan

T Hasegawa

Department of Clinical Pathology, Sapporo Medical University School of Medicine, Sapporo060-8543, Japan; hasetada@sapmed.ac.jp

The patient gave informed consent for this letter to be published.

\section{References}

1 Haeryoung K, Chanil P, Kwang-Hyup H, et al. Primary liver carcinoma of intermediate (hepatocyte-cholangiocyte) phenotype. J Hepatol 2004; 40:298-304

2 Theise ND, Yao JL, Harada K, et al. Hepatic "stem cell" malignancies in adults: four cases. Histopathology. 2003: 43;263-71).

3 Morinaga S, Nishiya H, Inafuku T. Yolk sac tumor of the liver combined with hepatocellular carcinoma. Arch Pathol Lab Med 1996:120:687-90

$4 \mathrm{Hu}$ L, Lau SH, Tzang CH, et al. Association of vimentin overexpression and hepatocellular carcinoma metastasis. Oncogene 2004;23:298-302

5 Kakizoe S, Kojiro M, Toshiro N. Hepatocellular carcinoma with sarcomatous change. Clinicopathologic and immunohistochemical studies of 14 autopsy cases. Cancer 1987;59:310-16.

\section{Metastasis of a caecal neuroendocrine carcinoma to the thyroid gland}

Metastatic tumours to the thyroid have been reported to arise from several organs. ${ }^{12} \mathrm{We}$ describe a unique case of caecal neuroendocrine carcinoma (NEC) metastatic to the thyroid gland, mimicking a primary medullary thyroid carcinoma (MTC).

A 56 year old woman was referred after complaining of dysphagia and hoarseness. 


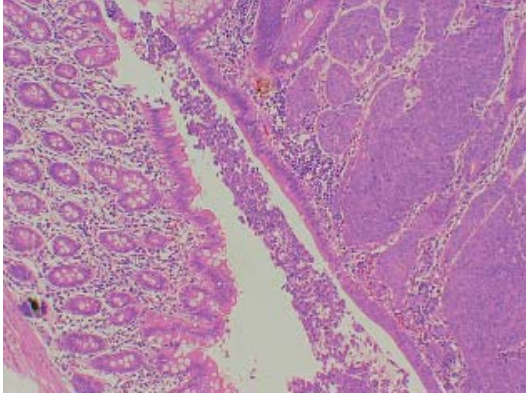

Figure 1 Primary neuroendocrine carcinoma of the caecum. Haematoxylin and eosin stain; original magnification, $\times 10$.

Fifteen months before, she underwent surgery because of a well differentiated caecal NEC, low grade malignant, with metastases to the left ovary, the omentum, and the abdominal lymph nodes (World Health Organisation classification). ${ }^{3}$ The tumour was composed of spindle shaped cells, exhibiting scanty eosinophilic cytoplasm, salt and pepper nuclei, and inconspicuous nucleoli (fig 1). Neoplastic cells showed intense reactivity with antibodies against CAM 5.2, AEl/AE3, cytokeratin 7, cdx-2, chromogranin A, synaptophysin, serotonin, and neurone specific enolase; there was weak reactivity for calcitonin and carcinoembryonic antigen. In contrast, no immunoreactivity was detected for thyroid transcription factor 1 or vimentin.

On examination, a firm nodule was felt in the left lobe of the patient's thyroid gland; attempts at fine needle aspiration biopsy did not yield adequate material for a cytological diagnosis. The patient underwent thyroidectomy, and histological examination disclosed a tumour in the left thyroid lobe, with the same pathological and immunohistochemical features as the previously excised caecal lesion (fig 2). Nonetheless, it was negative for Congo red, S-100 protein, and thyroglobulin stain; again, cdx-2 staining was positive, further confirming the caecal origin of this tumour (fig 3 ). Twenty one months after thyroidectomy, the patient died as a result of multiple organ failure.

To the best of our knowledge, this is the first case of a rare caecal NEC with metastasis to the thyroid to be reported. The differential diagnosis included several primary neoplasms. MTC is characterised by positive

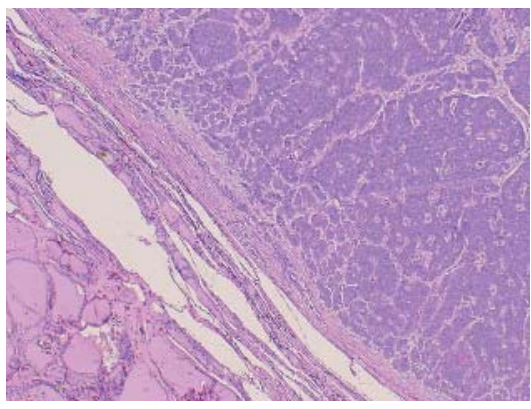

Figure 2 The caecal neuroendocrine tumour (right side of the figure) metastatic to the thyroid gland (on the left side) grew in a predominantly solid and trabecular architectural pattern, surrounded by a fibrovascular stroma. Haematoxylin and eosin stain; original magnification, $\times 10$.

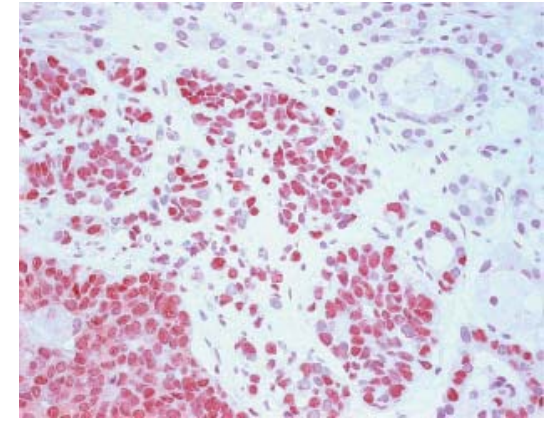

Figure 3 The thyroid metastasis was composed of spindle shaped cells with poorly defined cell borders, exhibiting scanty eosinophilic cytoplasm, salt and pepper nuclei, and inconspicuous nucleoli. The tumour cells showed intense nuclear staining for $\mathrm{cdx}-2$; in contrast, thyroid epithelium was negative for this marker. $\mathrm{Cdx}-2$ staining; original magnification, $\times 40$.

immunostaining for calcitonin ${ }^{4}$; nonetheless, calcitonin can also be produced ectopically. ${ }^{5}$ In our patient, weak positivity for calcitonin was found at immunohistochemical examination; however, staining for thyroid transcription factor 1, a marker of thyroid or lung origin, ${ }^{6}$ was negative, whereas cdx-2, a transcription factor involved in the proliferation and differentiation of intestinal epithelial cells encoded by a homeobox gene, ${ }^{7}$ was positive, excluding MTC. Paraganglioma was ruled out by both the intense reactivity of neoplastic cells for cytokeratins, and the absence of sustentacular cells, as shown by negativity for S-100 protein. ${ }^{8}$ Insular carcinoma could be excluded by the absence of a microfollicular pattern, the negative immunoreaction against thyroglobulin, and the positive immunostaining for neuroendocrine markers. Finally, a few cases of primary small cell carcinoma of the thyroid have been described, ${ }^{9}$ which share identical pathological and immunohistochemical features with primary lung small cell carcinoma. Some of them are positive for calcitonin, and are therefore regarded as small cell variants of MTC. In our patient, small cell carcinoma was ruled out firstly because of patient history and also by positive immunostaining for $\mathrm{cdx}-2$.

G Papi

Department of Internal Medicine, Section of Endocrinology, University of Modena and Reggio Emilia, Modena I-41012, Italy; papigiampaolo@ hotmail.com

S Corrado

Department of Forensic and Morphologic Sciences, Section of Pathology, University of Modena and Reggio Emilia

C Carani

Department of Internal Medicine, Section of Endocrinology, University of Modena and Reggio

Emilia

S L, Asa

Department of Laboratory Medicine and Pathobiology, University of Toronto, Toronto, Ontario,

Canada

\section{References}

1 Mortensen JD, Woolner LB, Bennett WA Secondary malignant tumors of the thyroid gland. Cancer 1956;9:306-9.
2 Nakhjavani MK, Gharib H, Goellner JR, et al. Metastasis to the thyroid gland. Cancer 1997;79:574-8

3 Solcia E. Endocrine tumours of the ileum, caecum, colon, and rectum. In: Solcia E, Kloppel G, Sobin $\mathrm{LH}$, eds. Histological typing of endocrine tumours, 2nd ed. Berlin Heidelberg: SpringerVerlag, 2000:66-7.

4 Murray D. The thyroid gland. In: Kovacs K, Asa S, eds. Functional endocrine pathology, Vol. 1. Boston: Blackwell, 1991:293-374.

5 Sano T, Saito H, Yamashi R, et al. Immunoreactive somatostatin and calcitonin in pulmonary neuroendocrine tumor. Cancer 1986;57:64-8.

6 Stenhouse G, Fyfe N, King G, et al. Thyroid transcription factor 1 in pulmonary adenocarcinoma. J Clin Pathol 2004;57:383-7.

7 Moskaluk CA, Zhang $\mathrm{H}$, Powell SM, et al. Cdx2 protein expression in normal and malignant human tissues: an immunohistochemical survey using tissue microarrays. Mod Pathol 2003:16:913-19.

8 Corrado S, Montanini V, De Gaetani C, et al. Primary paraganglioma of the thyroid gland. $J$ Endocrinol lnvest 2004;27:788-92.

9 Eusebi V, Damiani S, Riva C, et al. Calcitonin free oat-cell carcinoma of the thyroid gland. Virchows Arch 1990;417:751-7.

\section{Liesegang rings in inflammatory breast lesions}

We present two examples of Liesegang rings occurring in association with duct ectasia. Liesegang rings are a rare phenomenon usually found in association with cystic or inflammatory lesions, and may be mistaken for parasites.

The first patient, a 52 year old woman, had a radiological code 4 mass lesion on screening mammography. Needle core biopsy (NCB) showed breast tissue infiltrated by sheets of single cells, with abundant foamy cytoplasm and slightly eccentric nuclei. Cytological atypia was minimal and there was no significant mitotic activity. The cells were admixed with lymphocytes, plasma cells, and neutrophil polymorphs. Immunohistochemical studies showed that the lesional cells were strongly CD68 positive and cytokeratin negative, confirming the haematoxylin and eosin impression of an inflammatory process, and excluding histiocytoid carcinoma. The aetiology of the inflammatory process was not apparent on NCB and, in view of the radiological suspicion of malignancy, the patient proceeded to excisional biopsy. This revealed a $1 \mathrm{~cm}$ slightly irregular lesion with a white cut surface and yellow foci centrally, bordered by fatty breast tissue. Microscopically, the lesion was composed of an irregular dense aggregate of histiocytes, lymphocytes, plasma cells, and neutrophil polymorphs, as seen on NCB. Within the aggregate of inflammatory cells, foreign body type giant cells were identified, some of which were associated with round acellular structures. These structures typically comprised a double layered outer wall containing evenly spaced radial cross striations, surrounding dense amorphous non-refractile orangophilic material, interpreted as Liesegang rings (fig 1). There was evidence of fat necrosis and florid duct ectasia in the immediate vicinity. The overall histological appearances were thought to represent a predominantly histiocytic inflammatory process incorporating Liesegang rings, secondary to a ruptured ectatic duct. There was no evidence of malignancy.

The second patient, a 54 year old woman, had a radiological code 5 mass lesion in the upper inner quadrant of her right breast on 


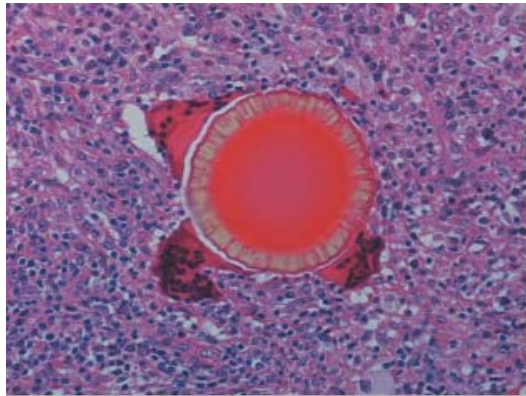

Figure 1 Liesegang ring characterised by a double layered outer wall containing evenly spaced radial cross striations, surrounding dense amorphous non-refractile orangophilic material. The ring has developed within an area of chronic inflammation and is associated with a foreign body giant cell reaction.

screening mammography. After a needle core biopsy diagnosis of invasive ductal carcinoma with associated ductal carcinoma in situ, she underwent therapeutic wire guided breast wide local excision and sentinel lymph node biopsy. The breast specimen showed a $15 \mathrm{~mm}$, grade 3, invasive ductal carcinoma, with extensive high grade ductal carcinoma in situ. Three sentinel lymph nodes were negative for metastatic carcinoma. The tissue lateral to the tumour showed features of duct ectasia. Liesegang rings were present in the lumen of one of the ectatic ducts and in the adjacent tissue with an associated foreign body type giant cell reaction.

Liesegang rings are laminated spherical ring-like structures that develop usually in relation to cystic or inflammatory lesions. The rings are typically composed of a mixture of calcium, iron, silicone, and sulfur and form by periodic precipitation from a supersaturated colloidal solution. ${ }^{1}$ Liesegang rings are rare and have been described primarily in the setting of renal cysts, ${ }^{2}$ but have also been observed occasionally in association with breast cysts, endometriotic lesions, and cysts at other sites. ${ }^{3-5}$ In the above two cases, the Liesegang rings were related to duct ectasia and in the first case were an integral part of the mammographic lesion. Liesegang rings may be mistaken for psammoma bodies or parasites. Liesegang rings lack the internal organs of true parasites and have a characteristic histological configuration, as described above. Accurate identification of Liesegang rings supports the diagnosis of a cystic or inflammatory process, and decreases the possibility of erroneous misdiagnosis as another type of pathological process.

K Gavin, N Banville, D Gibbons, C M Quinn Department of Histopathology, St Vincent's University Hospital, Elm Park, Dublin 4, Ireland; c.quinn@

Full consent was given for the publication of these cases.

\section{References}

1 Raso DS, Greene WB, Finley JL, et al. Morphology and pathogenesis of Liesegang rings in cyst aspirates: report of two cases with ancillary studies. Diagn Cytopathol 1998;19:116-19.

2 Katz LB, Ehya H. Liesegang rings in renal cyst fluid. Diagn Cytopathol 1990;6:197-200.

3 Gupta RK. Ringlike structures in fine needle aspirates from the breast. Cytopathology 1996;7:352-6.
4 Clement PB, Young RH, Scully RE. Liesegang rings in the female genital tract. A report of three cases. Int J Gynecol Pathol 1989;8:271-6.

5 Tuur SM, Nelson AM, Gibson DW, et al. Liesegang rings in tissue. How to distinguish Liesegang rings from the giant kidney worm, Dioctophyma renale. Am J Surg Pathol 1987; 11:598-605.

\section{Congenital bronchogenic cyst in the gastric mucosa}

We read with interest the letter by Rubio et al, "Congenital bronchogenic cyst in the gastric mucosa" in the March 2005 issue. ${ }^{1}$ In their report, the cyst they discovered contained pseudostratified ciliated epithelium with a lymphatic follicle. No cartilage was noted and no respiratory seromucous glands were mentioned. Although all bronchogenic cysts must have ciliated epithelium (pseudostratified ciliated columnar or cuboidal epithelium), they must also have cartilage or bronchial mucous glands. ${ }^{2-5}$

Foregut cysts include bronchogenic, oesophageal, gastroenteric, and pericardial types. The most common location for these cysts is in the mediastinum; however, cutaneous, cervical, diaphragmatic, abdominal, retroperitoneal, and gastric locations have all been described. Although gastroenteric and pericardial cysts are straightforward to differentiate, the distinction between oesophageal and bronchogenic cysts can be difficult because of their similar histological features, as a result of their close embryological development. All bronchogenic cysts must have ciliated epithelium (pseudostratified ciliated columnar or cuboidal epithelium). They also must have cartilage or bronchial mucous glands. Oesophageal cysts can have ciliated or non-ciliated epithelium of columnar, squamous, or mixed types. This epithelium sits on two well developed layers of smooth muscle with no cartilage or respiratory glands. When a cyst is only lined by ciliated columnar epithelium with none of the above mentioned distinguishing features, a foregut cyst is the appropriate description. ${ }^{2-5}$

\section{K Liang}

Bellevue Hospital, Department of Surgery, 27th Street and 1 st Ave, 15S5, New York City, New York 10016 ,

USA

J L Marks

Weill-Cornell Medical Center, Department of Surgery, New York City, New York 10021, USA

\section{References}

1 Rubio CA, Orrego A, Willen R. Congenital bronchogenic cyst in the gastric mucosa. J Clin Pathol 2005;58:335.

2 Salyer DC, Salyer WR, Eggleston JC. Benign development cysts of the mediastinum. Arch Pathol Lab Med 1977;101:136-9.

3 Sumiyoshi K, Shuji S, Munetomo E, et al. Bronchogenic cyst in the abdomen. Virchows Arch 1985;408:93-8.

4 Dahms BB. The gastrointestinal tract. In: Stocker JT, Dehner LP, eds. Pediatric pathology. Philadelphia: Lipincott, 1992:653-5.

5 Harvell JD, Macho JR, Klein HZ. Isolated intraabdominal esophageal cyst: case report and review of the literature. Am J Surg Pathol $1996 ; 20: 476-9$

\section{Expression of HIF- $1 \alpha$ in human tumours}

In their recent letter, ${ }^{1}$ van Diest and colleagues make a valid point that the expression of molecular markers in the literature is often discordant because investigators do not use standard methodologies. The use of tissue microarrays or whole tissue sections is one example of this, and van Diest and colleagues correctly point out that the core redundancy in tissue microarrays necessary for an accurate reflection of hypoxia inducible factor $\alpha$ (HIF-l $\alpha$ ) expression must be determined in a prospective fashion. Nevertheless, our evaluation of HIF- $1 \alpha$ staining was carefully controlled; we stained all tissues with a single antibody, at the same time, and used positive internal cell line standards on each section. ${ }^{2}$ The assumption that the analysis of HIF-l $\alpha$ expression in whole sections is prognostically superior to tissue microarrays is unfounded at this time. Indeed, a report by Torhorst and colleagues suggests that the assessment of biomarker status in arrayed tissue cores may carry greater prognostic value than assessment in whole sections. ${ }^{3}$

The objective of our analysis was to demonstrate that vascular endothelial growth factor (VEGF) is upregulated independently of activated HIF- $1 \alpha$ in most human tumours. This may imply constitutive overexpression or, more likely, reactive upregulation in response to other factors in the tumour microenvironment. The validity of this observation is not affected by the choice of tissue microarrays or whole sections. Indeed, a report by Mizukami and colleagues suggests that certain human cancers may exploit an HIF- $1 \alpha$ independent mechanism to upregulate VEGF in response to hypoxia.

In summary, we strongly support any move that would help to standardise the reporting of the expression of molecular markers in tissues. However, we stand by our observations that the upregulation of VEGF in human tumours is largely independent of HIF- $1 \alpha$ activation.

Department of Pathology, Genentech Inc, 1 DNA Way, South San Francisco, CA 94080, USA; adrianjubb@gmail.com

\section{References}

1 Van Diest PJ, Vleugel, Van der Wall E. Expression of HIF- $1 \alpha$ in human tumours. J Clin Pathol 2005; 58:335-6

2 Jubb AM, Pham TQ, Hanby AM, et al. Expression of vascular endothelial growth factor, hypoxia inducible factor $1 \alpha$, and carbonic anhydrase IX in human tumours. J Clin Pathol 2004;57:504-12.

3 Torhorst J, Bucher C, Kononen J, et al. Tissue microarrays for rapid linking of molecular changes to clinical endpoints. Am J Pathol 2001;159:2249-56.

4 Mizukami Y, Li J, Xhang X, et al. Hypoxiainducible factor-1-independent regulation of vascular endothelial growth factor by hypoxia in colon cancer. Cancer Res 2004;64:1765-72.

\section{CORRECTION}

Salashor S, Woodgett JR. The links between axin and carcinogenesis. $J$ Clin Pathol 2005;58:225-36. The third sentence of the abstract should read: "Overexpression of mutant axin..." and in fig 5 parts A and D are $\beta$ catenin and $\mathrm{B}$ and $\mathrm{E}$ are axin 1. The authors apologise for these mistakes. 